ISSN 2076-0752

www.mdpi.com/journal/arts

Review

\title{
Pleistocene Palaeoart of Asia
}

\section{Robert G. Bednarik}

International Federation of Rock Art Organizations (IFRAO), P.O. Box 216, Caulfield South, VIC 3162, Australia; E-Mail: robertbednarik@ hotmail.com; Tel.: +61-3-95230549; Fax: +61-3-95230549

Received: 8 May 2013; in revised form: 10 June 2013 / Accepted: 12 June 2013 /

Published: 19 June 2013

\begin{abstract}
This comprehensive overview considers the currently known Pleistocene palaeoart of Asia on a common basis, which suggests that the available data are entirely inadequate to form any cohesive synthesis about this corpus. In comparison to the attention lavished on the corresponding record available from Eurasia's small western appendage, Europe, it is evident that Pleistocene palaeoart from the rest of the world has been severely neglected. Southern Asia, in particular, holds great promise for the study of early cognitive development of hominins, and yet this potential has remained almost entirely unexplored. Asia is suggested to be the key continent in any global synthesis of 'art' origins, emphasising the need for a comprehensive pan-continental research program. This is not just to counter-balance the incredible imbalance in favour of Europe, but to examine the topic of Middle Pleistocene palaeoart development effectively.
\end{abstract}

Keywords: rock art; portable palaeoart; Pleistocene; figurine; bead; engraving; Asia

\section{Introduction}

There are thousands, perhaps tens of thousands, of publications on the Pleistocene 'art' of western Europe, but until 1992, no pan-continental study of the early palaeoart of Asia had ever been attempted (or, for that matter, of any other continent besides Europe) (Bednarik 1992a) [13]. The severely distorted record resulting from this significant, world-wide imbalance has been a major contributor to the slanted model of early global art development that has been promoted, which in turn has discouraged serious attempts to examine the available data outside of Europe. This distortion is reflected in the listing of dozens of European sites of 'Ice Age rock art' on UNESCO's World Heritage List, where not a single such site from any other continent is listed. Some of these sites, such as those in the Côa valley of Portugal or Siega Verde in western Spain, are not even of the Pleistocene 
(Bednarik 2009) [33]. All this feeds the illusion that 'art was invented in Europe', subconsciously reinforcing the European fantasy of cultural superiority. This is just one major effect of this imbalance, another being the unrealistic dogma of hominin cognitive evolution held by orthodox archaeology. For instance the 'African hoax' (the 'African Eve' model which ultimately derives from fraudulent claims; Bednarik 2011) [35] derives much support from this misconception. To appreciate the magnitude of the consequences of the disparity it could be considered how credible the discipline of plate tectonics would be if $99 \%$ of its attention were focused on France and Spain alone, or indeed how any scientific field would be viewed if it held such massive bias. That is precisely the way many current Pleistocene palaeoart studies need to be seen.

In a small effort to remedy a situation that is clearly detrimental to the credibility of the discipline, the currently available evidence of Pleistocene art-like practices in Asia is reviewed here. This follows the only two previous attempts to do so (Bednarik 1992a, 1994a) [13,21], which seem to have had little effect on the beliefs of most practitioners of the discipline. It also follows a similar pan-continental review of the Ice Age palaeoart of Africa (Bednarik 2013a) [36]. It bears repeating that traces of human behaviour of that period that are archaeologically defined as 'art' are probably not art in the modern Western sense, which is why the term 'palaeoart' is preferable to define them collectively. Palaeoart simply defines traces or objects that would in contemporary traditions be interpreted as manifestations of art, but whose real role is much more appropriately described as external storage of memory traces, as exograms. The concept of external engrams (engrams, or memory traces in the human brain, have never been demonstrated to exist; Lashley 1950; Thompson 1967, 1986, 1990; Thompson et al. 1976; Steinmetz and Thompson 1991; Steinmetz et al. 1987, 1992; Christian and Thompson 2005) [94,141-144,132-134,58] was first applied to non-figurative cave art (Bednarik 1987) [9]. Since certain forms in which they occur are readily identifiable on the archaeological record they provide the most comprehensive indices in estimating the cognitive complexity of hominins, but they can also demonstrate the inadequacies of archaeological inferences.

For instance it is clear that the faculty of self-awareness in a social animal would logically lead to strategies of consciously expressing individualism. Most such evidence is of a nature possessing very low taphonomic thresholds (Bednarik 1994b; but see McGrew and Marchant 1998; McGrew 2004 for apparent 'self-decoration' of a chimpanzee) [22,103,102], but beads and pendants are notable exceptions (Bednarik 1997, 2005, 2008a) [27,30,31] providing glimpses of very early self-adornment. The several species indicating degrees of self-awareness (De Veer and Van Den Bos 1999; Gallup 1970, 1998; Gallup et al. 2002; Heyes 1998; Keenan et al. 2003; Mitchell 1993, 1997, 2002) [62,73$75,85,89,105-107]$ are much the same as those shown to possess von Economo neurons (Seeley et al. 2006; Butti et al. 2009; Hakeem et al. 2009) [126,55,84]. The latter seem to occur in relatively large species with large brains and extensive social networks (Bednarik 2011) [35], and it may be that constructs of individuality evolved in tandem with these networks. It is difficult to see how social complexity could have developed beyond that of social insects without some level of self-awareness. Since self-awareness can safely be assumed to have been present in all hominin species, it helps account for the earliest known find implying recognition of iconic resemblance, the Makapansgat cobble (Bednarik 1998) [28]. Clearly, the pareidolic detection of human features presupposes apperceptive capability, in this instance some 2.95 million years ago (Bednarik 2013a: Figure 1) [36]. The lack of subsequent, more direct indications of self-awareness for much of the remaining history of 
hominins is apparent, but in view of the generic coarse resolution of the available record as well as the relevant taphonomy (not to mention systemic archaeological neglect of such evidence) it is to be expected. Taphonomic logic (Bednarik 1994b) [22] facilitates the theoretical reconstruction of the 'missing' component of the archaeological record, but the starting point of it is still the available empirical evidence. However, if that record is tainted by the ignorance of commentators, as well as by its 'adaptation' to comply with a false dogma (such as the Eve hypothesis), it is particularly important to set the record straight. That has been done in respect of Africa (Bednarik 2013a) [36] and will be done for the remaining continents. Here it is Asia's turn to submit to close examination. The largest continent's Pleistocene palaeoart will be considered, beginning in the north, in Siberia, followed by the remaining regions, essentially travelling around the continent clockwise.

Figure 1. Eight of the ivory objects from Mal'ta, near Irkutsk, Siberia, probably close to 15,000 years old.

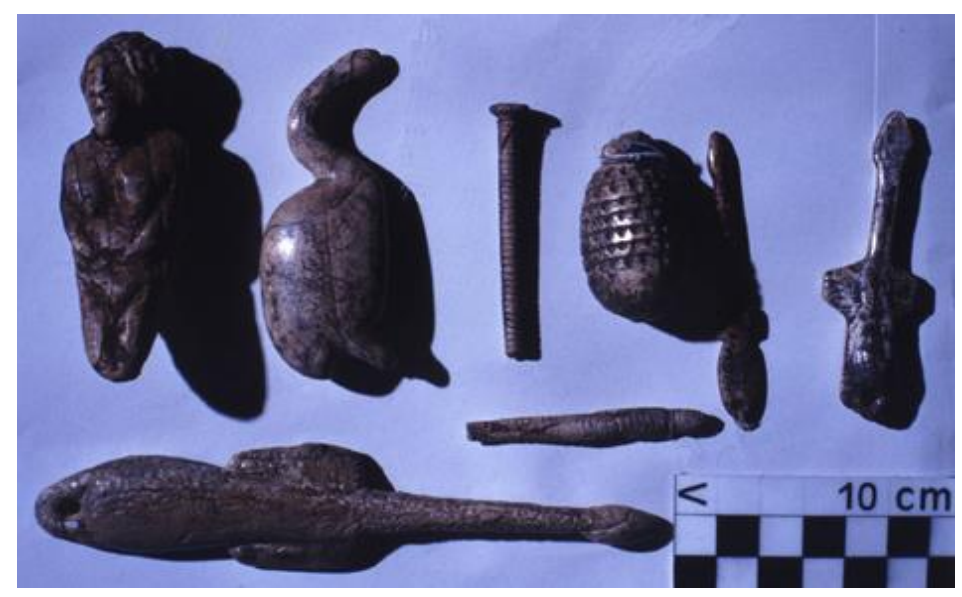

\section{Siberia}

Besides Israel, Siberia is the only region of Asia whose Pleistocene art has traditionally attracted a reasonable degree of attention, however limited. In central Siberia, in the Irkutsk region, Palaeolithic research commenced in 1871, i.e., within a few years after it had begun in Europe, and it has recorded portable palaeoart at over twenty sites so far. Where this material can be plausibly attributed to the Pleistocene, it seems to belong mostly to the second half of the Upper Palaeolithic. The best-known site is Mal'ta, excavated both before and after World War II. Located on a left tributary of the Angara, the Belaya River, the site's Palaeolithic layer is often dated to between $24 \mathrm{ka}$ (24,000 years) and $23 \mathrm{ka}$ $\mathrm{BP}$, but a radiocarbon date of 14,750 $\pm 120 \mathrm{BP}$ may be more relevant (Boriskovski 1984: 358) [53].

Portable Pleistocene palaeoart finds have also been reported from the Irkutsk hospital site (Irkutskii gospital'), and from several further sites on the Angara river (Buret', Krasnyi Yar, Ust'-Kova and Verkholenskaya Gora). They also occur at sites on the upper Yenisey river, of which the Angara is the major tributary (Afontova Gora II, Afontova Gora III, Maininskaya, Dvouglazka Cave, Tachtik, Kokorevo, Novosselovo and Atchinskaya); at two sites on the upper Ob river (Ust'-Kanskaya and Denissova Cave, the latter site having recently received much attention for its considerably earlier hominin; Krause et al. 2010) [91]; at two sites on the Upper Lena (Shishkino and Tal'ma); at two more south of Lake Baykal (Oshurkovo and Tolbaga); and at one site on the Irtysh River (Cherno-Ozer'e). 
There is also a single site on the coast of the Arctic Ocean, at the mouth of the Indigirka river (Berelekh, apparently the northernmost known Palaeolithic site in the world). The evidence from these sites is briefly summarised.

Figure 2. Numbers 3 (left) and 4 of the ivory figurines from Buret', central Siberia, each seen from front and back; scale in cms.

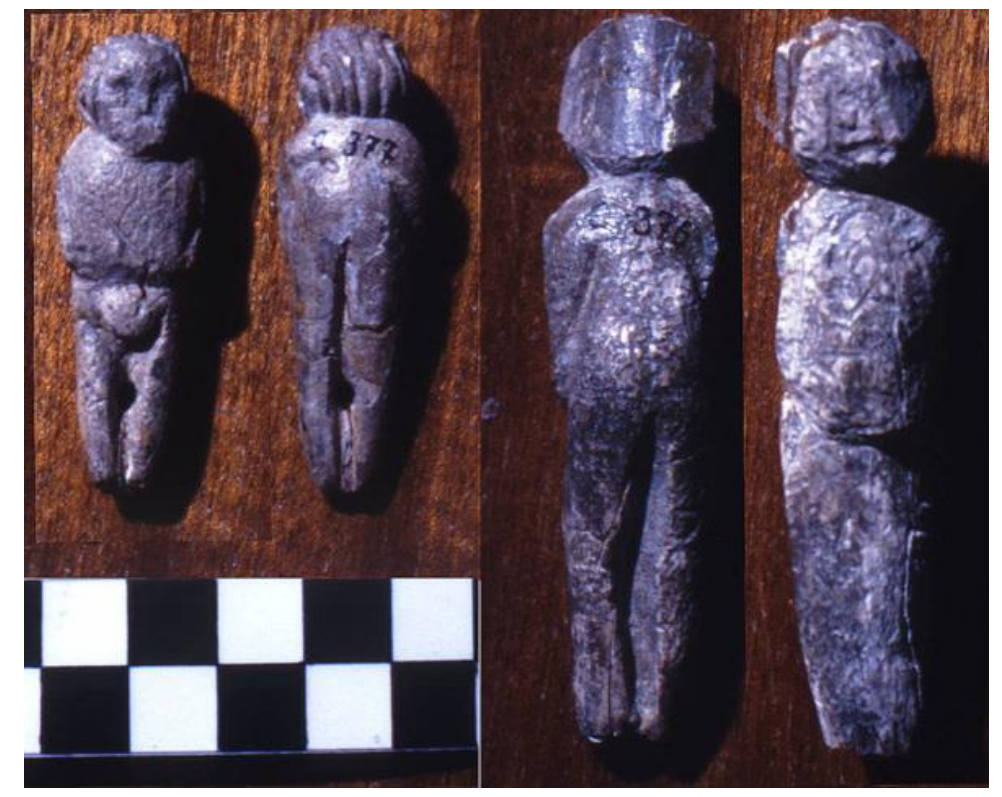

The perhaps best-known corpus of Pleistocene art from Asia consists of the 33 anthropomorphous sculptures from Mal'ta and Buret', traditionally described as female figurines (Figures 1 and 2). This predilection expresses the Eurocentric preoccupation with the 'Venus' figurines of western, central and eastern Europe, and commentators often consider them as part of a perceived Upper Palaeolithic tradition extending from the Pyrenees to Siberia. However, there are two problems with this popular notion. First, although the female figurines of Europe have given rise to numerous mutually exclusive explanations, they are rather more diverse than implied in much of the commentary (cf. Gvozdover 1989; Bednarik 1989, 1990a, 1996a; Duhard 1990; Gimbutas 1991; Dobres 1992; Russell 2006) $[83,10,11,25,64,78,63,125]$. Second, there is also considerable diversity among the Palaeolithic anthropomorphs from Siberia, in several respects, and as a group they are sufficiently different from the supposedly female figurines of France, central Europe and European Russia/Ukraine to prompt separate consideration (Bednarik 1990a) [11]. For instance, none of the Siberian specimens indicates abdominal enlargement and few offer clear enough evidence of gender to collectively define them as female. Breasts are often lacking, and a vulvar cleft is suggested only on one, Mal'ta No. 5. About $40 \%$ of them show some facial details, which are frequently lacking on the so-called 'Venus' figurines of Europe, and several appear to be fully clothed (Figure 3). Of the latter, only one is perforated, while many of the generally smaller Siberian specimens still bear perforations on the lower end, or the same is broken off. Indeed, a large part of the Palaeolithic art of Siberia is perforated. For instance, this applies to $76.6 \%$ of the largest assemblage $(n=31)$, that of Mal'ta - not counting those items that bear no perforation now, but may have been perforated in the past, or that have been attached to a string by other means, such as the distinctive notched beads from Buret' and Mal'ta. Most Siberian 
anthropomorphous sculptures of the Pleistocene are made from mammoth ivory, the two exceptions being Buret' No. 5, which is from pale-green steatite, and a clay figurine from Maininskaya. Most of the Siberian specimens have no 'stylistic' counterparts in Europe, and they are also distinctly different from many of those in European Russia. Only the highly stylised Krasnyi Yar sculpture deserves a comparison with European finds, in that it seems to resemble the Magdalenian figurines and engravings of central and eastern Europe which have been collectively defined as stylised female figures, including those from Ölknitz, Petersfels, Mauern, Nebra, Trasimeno, Gönnersdorf, Wandersleben, Mezin and Pekarna (see Bednarik 1990a for references and discussion) [11].

Figure 3. Three small figurines from central Siberia: (a) Mal'ta No. 13; (b) Mal'ta No. 27 (both are of ivory); (c) Buret' No. 5 (of steatite).

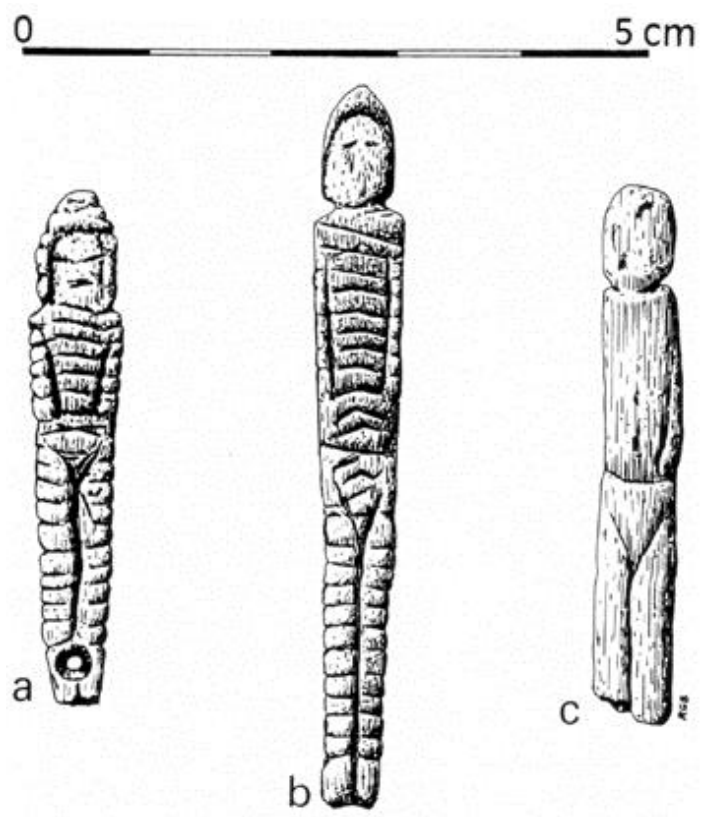

The same applies to the other forms of portable art from the Siberian sites. The distinctive 'flying bird' pendants (13 from Mal'ta, one from Buret') have no counterparts at all in Pleistocene Europe, nor have the other three bird pendants, the five nail-like pins, and several further, apparently decorative items, particularly from Mal'ta (Figure 1). 'Ornamental' objects, likely to have served as body adornment, clearly dominate the Siberian assemblages, making up $>80 \%$. There are numerous rods, spindles and possible hairpins, and other objects of jewellery such as headbands, bracelets, breast-ornaments, necklaces and pendants. Even most of the human figurines were probably pendants, interestingly designed to hang upside down, and evidence of them having been suspended by a string has been observed (Bednarik 1990a: 134-135) [11]. They differ significantly from those of European Russia and central/western Europe, most of which were too large to use as pendants, with one limestone specimen from Kostenki weighing several kilograms (Bednarik 1990a: Figure 1f) [11]. In fact only one European specimen was meant to be suspended, as indicated by the location of its perforation, from Sireuil in France. The Buret' site is located on the right bank of the Angara, near its tributary Belaya, and its occupation is at 14.8 ka roughly contemporary with Mal'ta.

Afontova Gora II (perhaps 20.9 ka old), Krasnyi Yar, Buret' and Mal'ta have yielded perforated disc beads, while perforated animal teeth occur at Verkholenskaya Gora and are especially numerous 
at Afontova Gora II. Decorative patterns of various types occur on many artefacts, including evenly spaced notches on edges. Incised engravings are comparatively rare, and when they do occur they are usually restricted to geometric arrangements, such as that on the large, centrally perforated Mal'ta ivory plaque (Figure 4), on the Oshurkovo pendant (Figure 5), an incised bone from the same site, two of the circular discs from Afontova Gora II, another circular disc from Afontova Gora III (engraved on both faces with radial patterns and circles; Figure 6), and four intricately decorated objects from Irkutskii gospital'. A distinctive feature are notches along edges, which are less common at the European Russian sites of the Upper Palaeolithic. The only unambiguous two-dimensional figurative art known from Pleistocene Asia are two Siberian depictions of 'mammoths'. One of these is on a perforated ivory plaque from Mal'ta (Figure 7), the other on a juvenile mammoth tusk from Berelekh, the northernmost site (Figure 8). Although there is human occupation evidence of the final Pleistocene at the latter site, it should be noted that the mammoth survived to at least 4000 years BP in the wider region (at Wrangel Island, on the same latitude but $1100 \mathrm{~km}$ to the east; Vartanyan et al. 1993) [147]. Therefore mere depiction of the mammoth is not necessarily proof for Pleistocene age, nor is the use of mammoth ivory. However, the mammoth-like sculpture from Ust'-Kova, at the confluence of the Kova river and the Angara is 23.9 ka old, found with bone beads, pendants of animal teeth and a geometric design (Vasilevski and Drozdov 1983) [148]. Mammoth ivory can also be found in various undoubted Holocene contexts of Siberia, at least until the Bronze Age, having presumably been salvaged from frozen carcasses or fossil remains (Bednarik 1993a) [17].

Figure 4. The centrally perforated ivory plaque from Mal'ta, engraved on both sides.

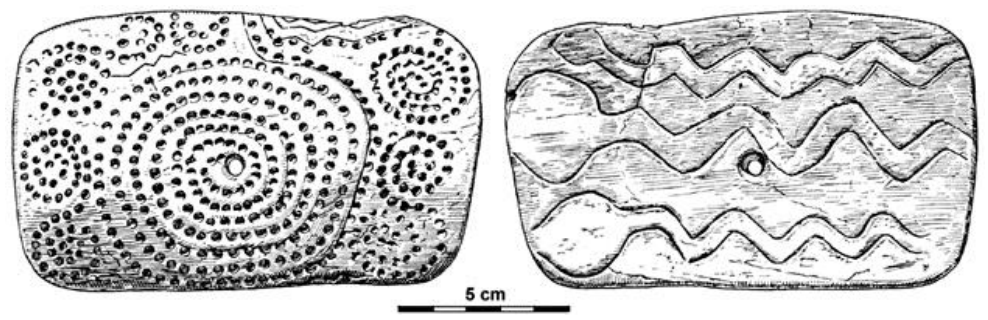

Figure 5. The notched pendant from Oshurkovo, near Ulan-Ude, southern-central Siberia, engraved on both sides.

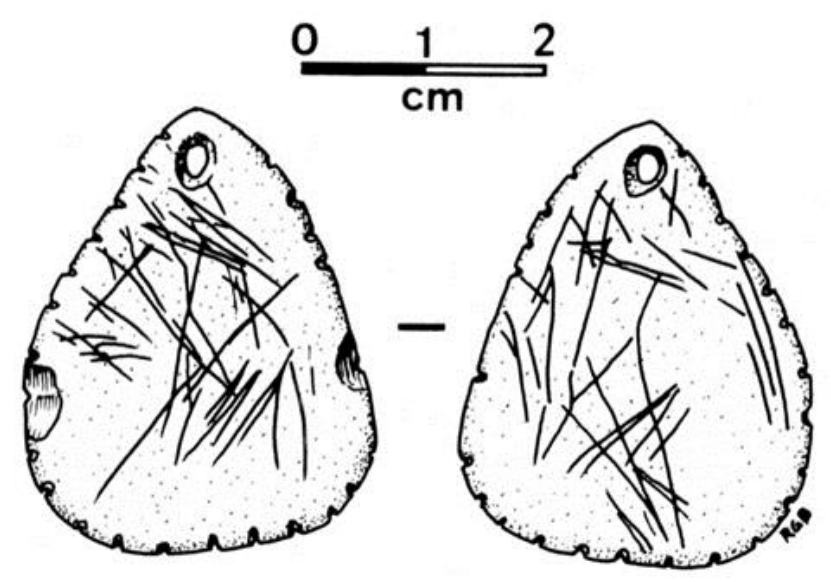


Figure 6. Both sides and section of engraved ivory disc from Afontova Gora III, westerncentral Siberia.

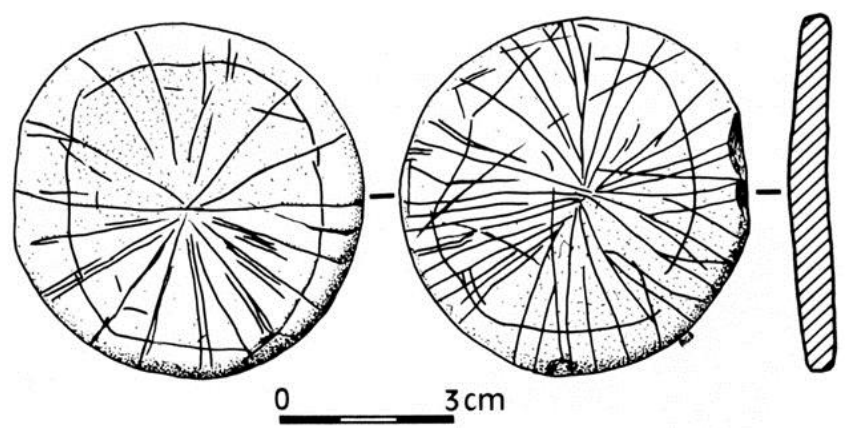

Figure 7. Presumed mammoth engraving on a perforated ivory plaque from Mal'ta, central Siberia.

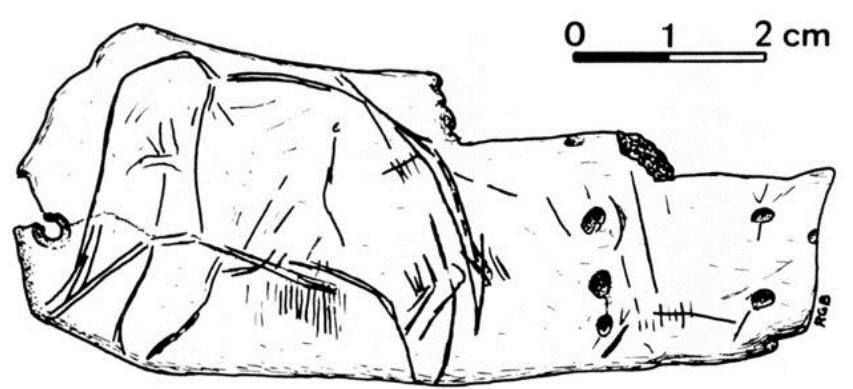

Figure 8. Presumed mammoth engraving on a mammoth tusk from Berelekh, Indigirka river in far-northern Siberia.

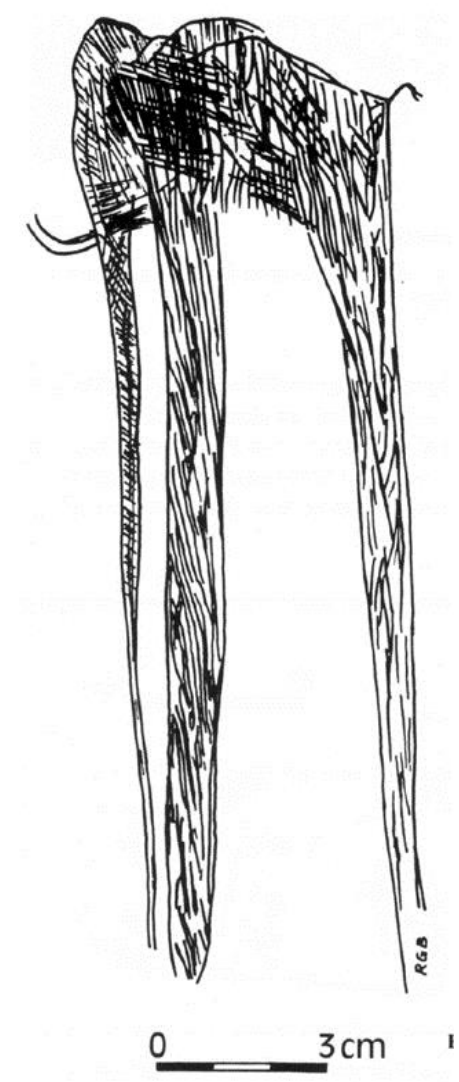


Three-dimensional iconography, however, occurs widely in Siberian mobiliary palaeoart of the final Pleistocene. One of the most significant finds is the sculpted animal head from Tolbaga. It is carved on a natural projection of a second vertebra of a woolly rhinoceros (Coelodonta antiquitatis). Microscopic examination of tool marks has shown how the head, thought to resemble that of a bear, has been carved with stone implements. Though produced with an economy of effort, the sculpture is sophisticated and of strikingly naturalistic appearance (Figure 9). Tolbaga is located on the right bank of the Khilok river and was excavated by Okladnikov in the 1970s, and two dates were secured from bones: $34,860 \pm 2100 \mathrm{BP}$ and 27,210 $\pm 300 \mathrm{BP}$. Abramova (1990) [1] argues that the older of the two dates is the more likely to refer to the carved vertebra. That would make it one of the oldest known naturalistic sculptures in the world.

Figure 9. Presumed head of a bear carved on a woolly rhinoceros vertebra from Tolbaga, south of Lake Baikal, Siberia, probably about 35,000 years old.

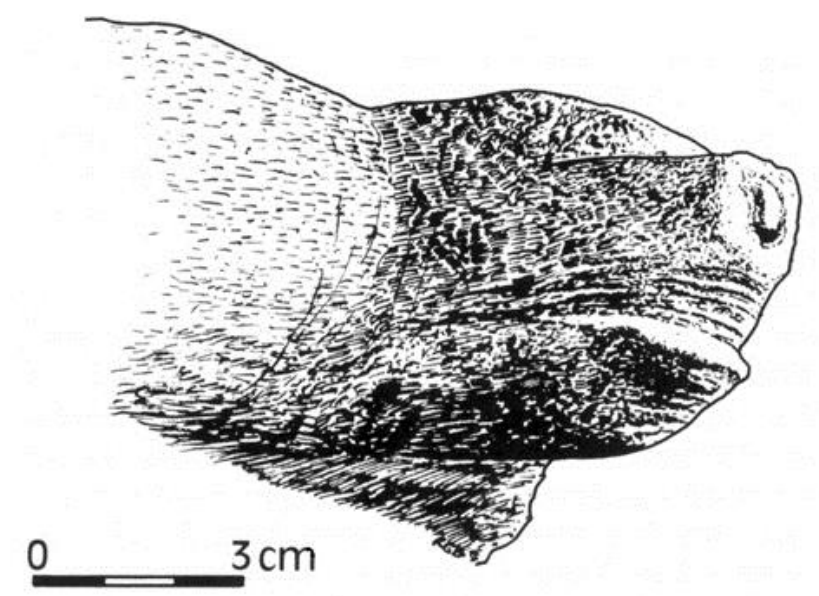

Turning next to rock art, a few rock paintings at the major petroglyph and pictogram site Shishkino and one motif at Tal'ma have often been described as being of the Upper Palaeolithic. Shishkino extends over almost $1 \mathrm{~km}$ along cliffs on the right bank of the Lena river downstream of Kačug and features about 2730 recognisable motifs. Tal'ma is a small petroglyph site on a left tributary of the Lena, further north, and has been proposed to include the presumed figure of a rhinoceros. However, neither the published recording of this figure (Okladnikov 1977: Figures 56, 57) [115] nor the quite different actual pigment traces on the rock at the Tal'ma main site resemble such an animal (Figure 10). Similarly, the supposedly equid and bovine animal paintings at Shishkino (Okladnikov 1959; Okladnikov and Saporoshskaya 1959) [114,116] are almost certainly much younger than the end of the Upper Palaeolithic (Bednarik and Devlet 1992) [39], and there is no indication that they depict species endemic to the Pleistocene (Figure 11). Both sites are fully exposed to the elements and their paintings should not be expected to be more than a few centuries old. Moreover, the fine sandstone weathers rapidly and most if not all petroglyphs in the region are clearly of Historic antiquity.

Even the Pleistocene age of the paintings in Kapova and Ignatiev Caves, on the European side of the Ural watershed and first questioned by Bednarik (1993a) [17], is doubtful, not only because the basis of purported faunal depiction has been queried in Siberia, but also because Steelman et al. (2002) [131] have provided three Holocene radiocarbon dates from Ignatievskaya. A supposed 
mammoth pictogram of charcoal pigment yielded a result of $7370 \pm 50$ years BP, and two other charcoal motifs at $7920 \pm 60 \mathrm{BP}$ and $6030 \pm 110 \mathrm{BP}$ respectively support this dating. Several explanations are possible: the first image may not be of a mammoth, the dates may be erroneous, the depiction may have been inspired by a frozen carcass, or the mammoth survived in the Urals well into the Holocene.

Figure 10. The petroglyph panel of the Tal'ma site, central Siberia, bearing also a presumed pictogram of a woolly rhinoceros. However, the pigment patch does not resemble that animal and may be natural discoloration.

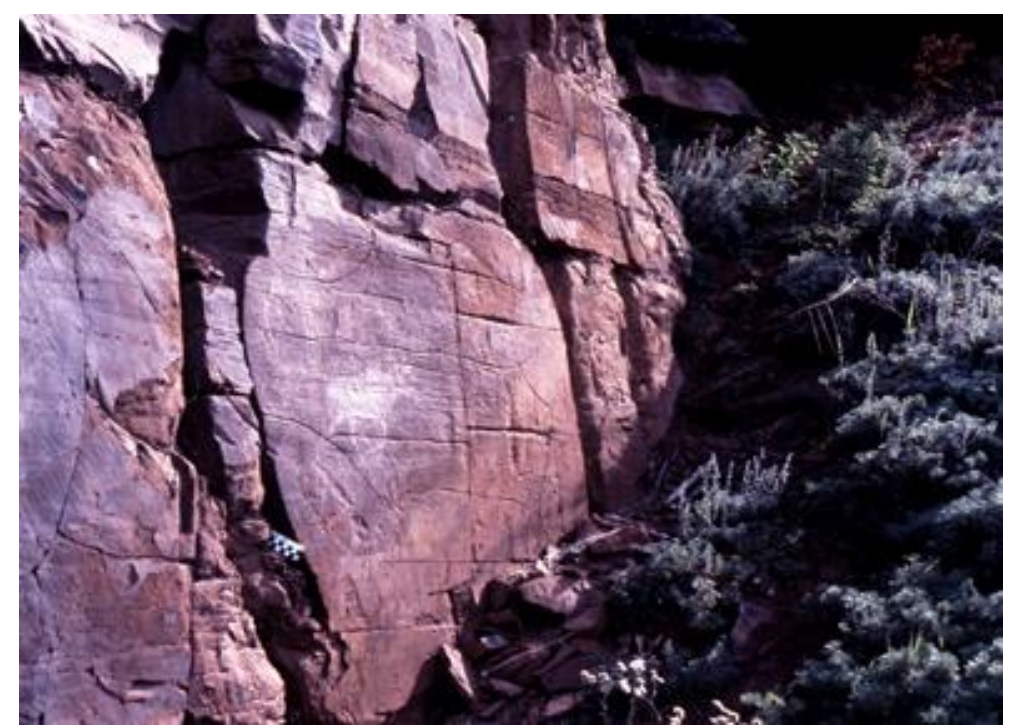

Figure 11. Zoomorphic pictograms at the large petroglyph site Shishkino on the Lena river, claimed to be of the Pleistocene. They are very recent, however.

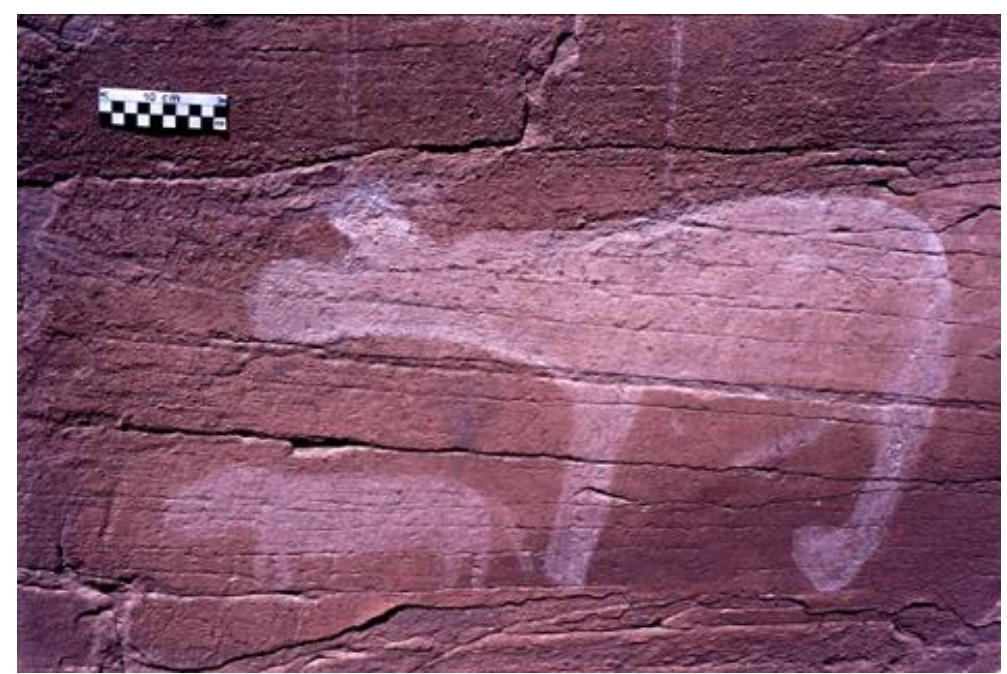

\section{Eastern Asia}

The earliest possibly non-utilitarian evidence from eastern Asia has been provided by Zhoukoudian Site 1, south-west of Beijing, which has yielded about twenty clear quartz crystals, including a prism with all crystal facets intact (Pei 1931: 120) [118]. Lower Palaeolithic quartz crystals have also been 
reported from sites in South Africa, India, Israel and Austria (Bednarik 1992b) [14]. Zhoukoudian Site 1 is part of a complex of twenty-six sites, and has also yielded the largest sample of Homo erectus remains (most of which disappeared in the Second World War) and very early but long controversial evidence of fire use. In view of the much earlier, clear-cut proof of controlled fire use in Wonderwerk Cave, South Africa (Beaumont 2011; Bednarik 2011: Figures 6.1, 6.2) [7,35], there is no longer any need to question the Zhoukoudian evidence. Stone spheres have also been frequently found in the deposits containing the Homo erectus finds, but while they tend to be grapefruit sized elsewhere, for instance at Lantian, they appear to be somewhat smaller at Zhoukoudian Site 1, of around 6-8 cm diameter.

Another Chinese find of very early palaeoart comes from Xinglongdong Cave in the Three Gorges region (Gao et al. 2004) [76]. It refers to one of two excavated stegodon (Stegodon orientalis) tusks, which are from different animals but have apparently been deposited together. One has numerous markings near its tip, some of which appear to be deliberate because they are branching and were made with stone tools; others seem to be taphonomic. A human tooth and stone tools have been recovered from same layer, dated to 120-150 ka BP by uranium-series analysis.

Numerous Palaeolithic engravings on bone have been reported, especially from the Shiyu site, Shanxi Province. This large occupation site dates from the Middle/Upper Palaeolithic interface, comprising two major occupation horizons which seem typologically identical, and which date from about 28 and 32 ka BP respectively. One of about 600 marked bone objects from both horizons has been published as depicting an engraved hunting scene (You Yuzhu 1984) [154], but none of the many specimens this author has examined has actually been engraved by human hand. The entire assemblage bears taphonomic (and thus natural) markings (Figure 12), which are basically of four types: tooth marks, clastic gouge marks, mycorrhizal root marks and abrasion marks. However, one item from the upper level at Shiyu is relevant here. It is one half of a broken stone disc that has been drilled through the centre (Figure 13), and was presumably used as an item of body adornment (Bednarik and You Yuzhu 1991) [48]. Very similar objects have been found at Siberian, Russian and Japanese sites of the Upper Palaeolithic.

Figure 12. Taphonomic (natural) marks on a horse humerus fragment from the Shiyu site, central China, that have been interpreted as depicting two hunting scenes, c. 28,000 years old.

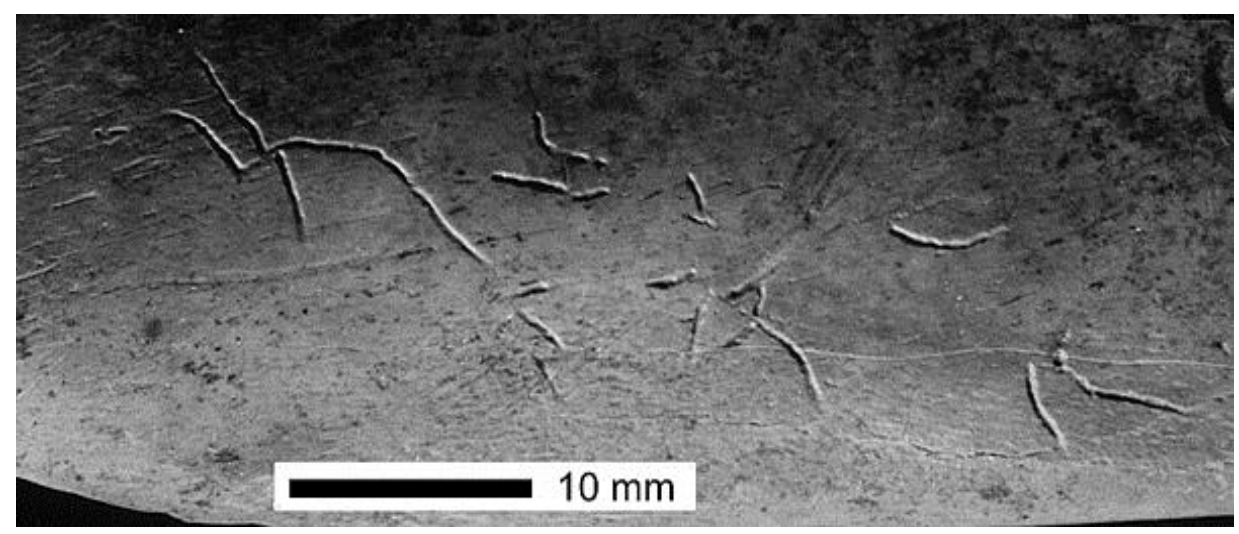


Figure 13. Three views of a drilled and fractured stone pendant from the Shiyu site.

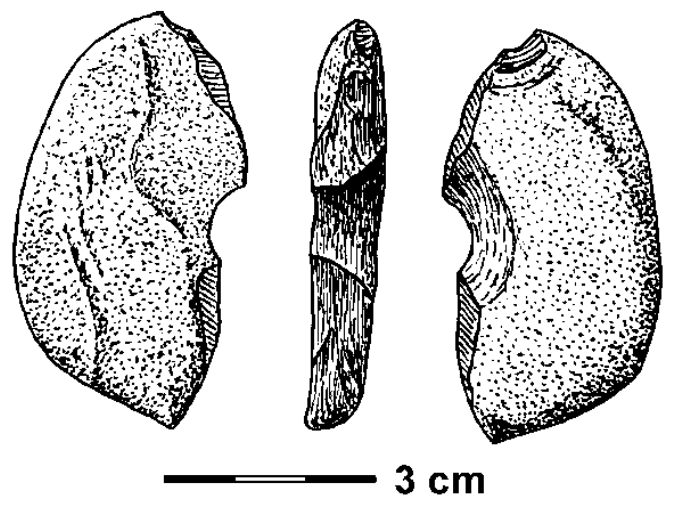

Shuidonggou Locality 1 in Lingwu County, Ningxia Hui Autonomous Region, was the first Palaeolithic site to be discovered in China, in 1920. Although its final Pleistocene stratigraphy has yielded a series of contradictory OSL dates from the site's Lower Culture unit, ranging from about 15.8 to $35.7 \mathrm{ka}$ (Liu et al. 2009) [98], Th-U dating of horse teeth points to an age of 34 to $38 \mathrm{ka}$ (Chen et al. 1984) [56]. The only radiocarbon date from the horizon, from charcoal, is $36,200 \pm 140$ years BP (Fei et al. 2012) [68]. Like the Shiyu site, the Shuidonggou lithic industry is transitional between Middle and Upper Palaeolithic typologies. Recently an engraved siliceous limestone fragment was discovered among remains excavated in 1980, bearing a set of eight distinct linear markings. The grooves on the 68-mm-long stone (Figure 14) were studied microscopically and are judged to have been made with stone implements (Fei et al. 2012) [68]. As elsewhere in the region's Palaeolithic occupation deposits, ostrich eggshell was also found in the site's Lower Culture unit, including one bead made from this material. Disc beads made from ostrich eggshell occur also in the nearby Gobi desert as surface finds and are attributed to the final Palaeolithic industry exemplified at Shubarak-usu.

Figure 14. Two views of engraved stone and close-up of the markings, from Shuidonggou Locality 1 , central China, probably about 36,000 years old.

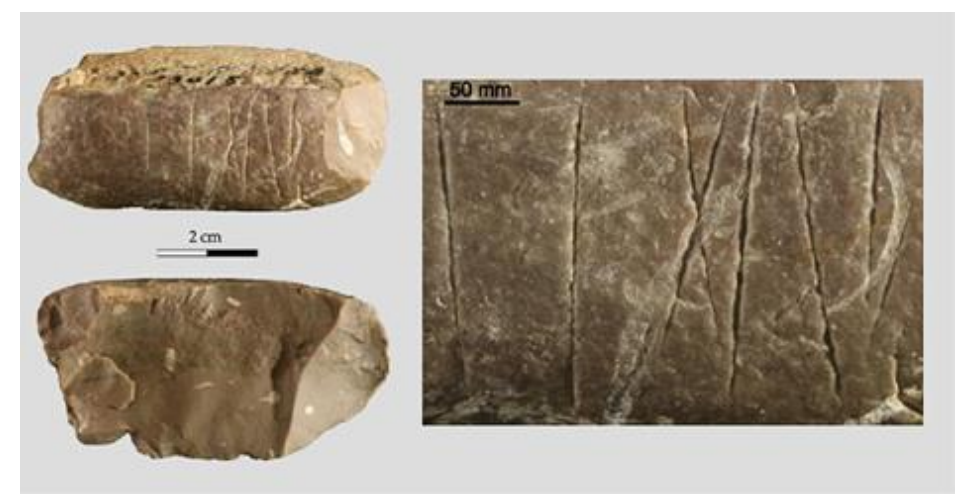

One of the sites of the Zhoukoudian complex is the Upper Cave, a natural bridge containing two Upper Palaeolithic occupation deposits, dating roughly to $13 \mathrm{ka}$ and $18 \mathrm{ka}$ BP respectively. These have yielded numerous haematite lumps and over 120 perforated objects (Bednarik and You Yuzhu 1991) [48]. They include beads made of deer and fox teeth, shells, fish vertebrae, perforated pebbles and five polished tubular sections of bird bones on which parallel lines are engraved. Ochre has also 
been found around interred human skeletal remains in the Upper Cave, but wear facets or striations have not been noted on the pigment pebbles.

The only item of more intricate Pleistocene art so far found in China is an engraved antler fragment from Longgu Cave, Hebei Province (Bednarik and You Yuzhu 1991; Bednarik 1992c) [48,15]. It is extremely well made, bearing three distinctive geometric patterns which were infilled with red pigment. The object is 13,065 \pm 270 years old, according to a small sample from the actual specimen. Made from a 134-mm-long fragment of Cervus elaphus canadiensis antler, the object has been carefully fashioned with stone tools to create the three separate designs (Figure 15). Particularly noteworthy is the occurrence of an elaborate guilloche pattern, which is most unusual but does occur in the exclusively geometric art of the Jarawas of the Andaman Islands (Bednarik and Sreenathan 2012) [47]. The complete stylistic isolation of this sophisticated object provides inkling of how limited the understanding of Pleistocene palaeoart remains in Asia.

Figure 15. Three carefully engraved complex patterns and their rolled-off recording, on a 13,000-year-old deer's antler fragment, from Longgu Cave, eastern China.
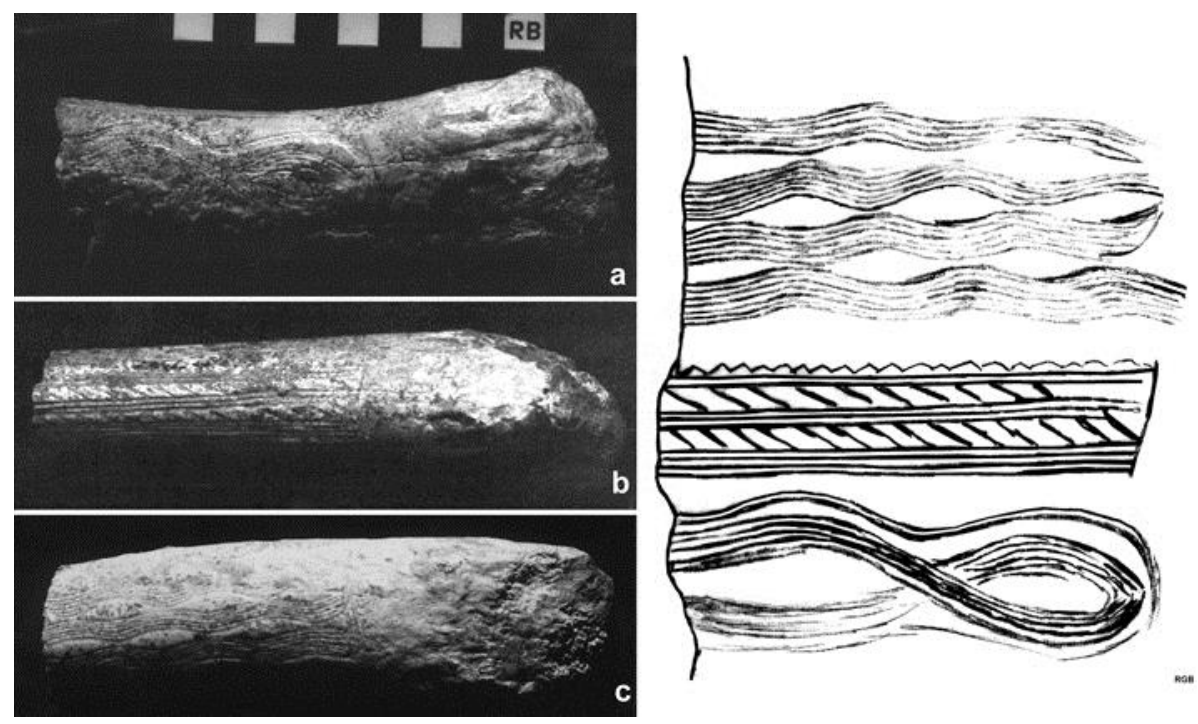

Several claims to have identified extinct fauna in Chinese rock art (e.g., You 1984; Gai 1986: 415-424; Liu 1991; Chen 1991: 126; Li 1992) [154,70,99,57,97], which would date the art to the Pleistocene - in one case even to the Tertiary - have been refuted (Wang 1984; Bednarik and Li Fushun 1991; Bednarik 1993a; Tang 1993) [151,46,17,137]. Nevertheless, as in India it seems likely that Pleistocene petroglyph traditions will be identified eventually. That possibility is reinforced by the dating of cupules at the Jiangjunya site, Jiangsu Province, to approximately $11 \mathrm{ka} \mathrm{BP}$ (Tang and Mei 2008; Tang 2012) [140,138]. Cupules appear also in numerous Holocene contexts in China, for instance on dolmen, but there is a universal trend, in all continents, for the oldest petroglyphs being primarily cupules (Bednarik 2008b) [32]. However, considerably more research is required before the presence of Pleistocene rock art in China can be clarified (Figure 16).

Of interest here is a recent report from Myanmar, of cupule panels in a limestone cave being covered by stalagmites and other speleothems (Aung 2013) [4]. Although there is no indication of a Pleistocene antiquity, it is relevant that in India vertical panels of cupules can be of extremely great ages (see below). A claim for Pleistocene petroglyphs based on the perceived identification of depicted 
fauna, similar to those in China, has also been made in South Korea (Sohn Pow-Key 1981) [128]. The same author had previously reported portable art from the Korean Middle Palaeolithic (Sohn Pow-Key 1974) [127] but both these reports have not been independently checked. Similarly there have been such claims from Mongolia and to the west of China, from central Asia, but none seem to be credible.

Figure 16. Early petroglyphs at Helanshan, Ningxia Hui, but of the Holocene.

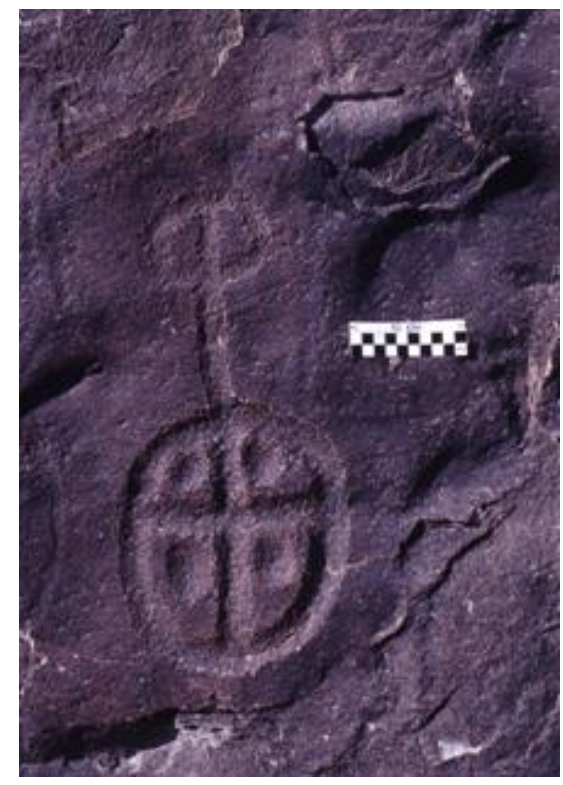

Although Japan is claimed to have been occupied by humans at least since the Penultimate Glaciation, Pleistocene art evidence remains extremely scarce in that country. The few available art objects are of stone. They consist of a perforated stone disc from the Debari site in Mie Prefecture (Bednarik 1994a) [21], reminiscent of that from Shiyu, China; a polished triangular stone object from the Deguchi Kanezuka site in Chiba Prefecture (Okamura 1992) [113]; and the engraved pebbles from layer IX in the Kamikuroiwa rockshelter, Ehime Prefecture, which is of the Incipient Jomon period and has been dated to over 12,000 years BP (Aikens and Higuchi 1982) [2]. These kokeshi (wooden Japanese dolls lacking arms and legs) are of natural pebbles with engravings which seem to represent breasts and skirts (Figure 17). The Jomon tradition produced the earliest decorated ceramic vessels in the world and is Mesolithic rather than Palaeolithic, but its early phase is of the Pleistocene.

Figure 17. Engraved pebbles of the Incipient Jomon of Kamikuroiwa rockshelter, Japan, of the final Pleistocene.

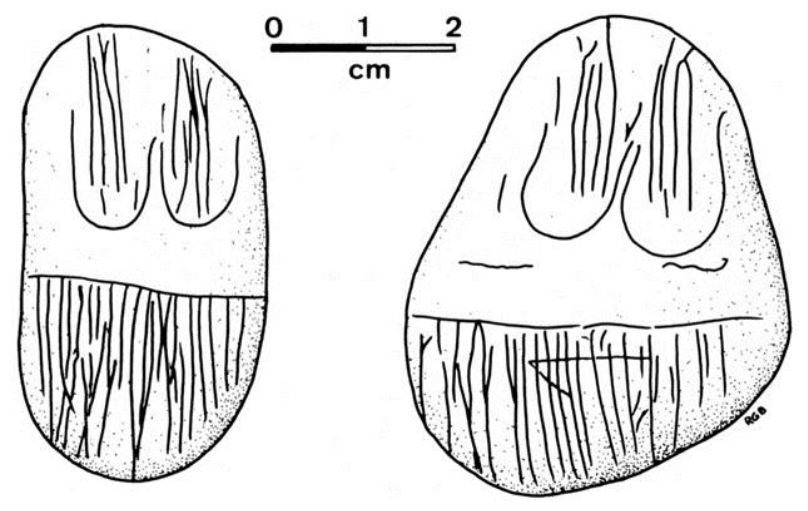




\section{India}

As in China the relevant finds begin with quartz crystals and haematite of the Lower Palaeolithic, notably the Acheulian. Six small quartz crystals have been recovered at Singi Talav, Didwana region of the Thar Desert in Rajasthan, from the base of the Lower Acheulian deposit (Gaillard et al. 1983; d'Errico et al. 1989) [72,60]. Chronostratigrapically the horizon is thought to be in the order of $800 \mathrm{ka}$ old (Gaillard 2006) [71]. The crystals measure from 7 to $25 \mathrm{~mm}$ in length, too small to have been used as tools, and they are almost entirely unmodified (Figure 18). Re-fitting them was impossible, and they differ so much in mineralogical purity that they are not assumed to have come from the same geode. Thus they have been brought to the site independently and were apparently collected for their visual qualities, as at several other Acheulian sites. Haematite pebbles occur frequently in Acheulian deposits of India (Paddayya 1982) [117], and there is one small specimen from Hunsgi which bears a wear facet with distinctive but fully patinated striation marks, suggesting that it has been used as a crayon to colour or mark a rock surface (Bednarik 1990b) [12]. Again, such finds are frequent in the Lower Palaeolithic in other parts of the world.

Figure 18. Small quartz crystals from Singi Talav, Rajasthan, India, which are manuports of the Lower Acheulian.
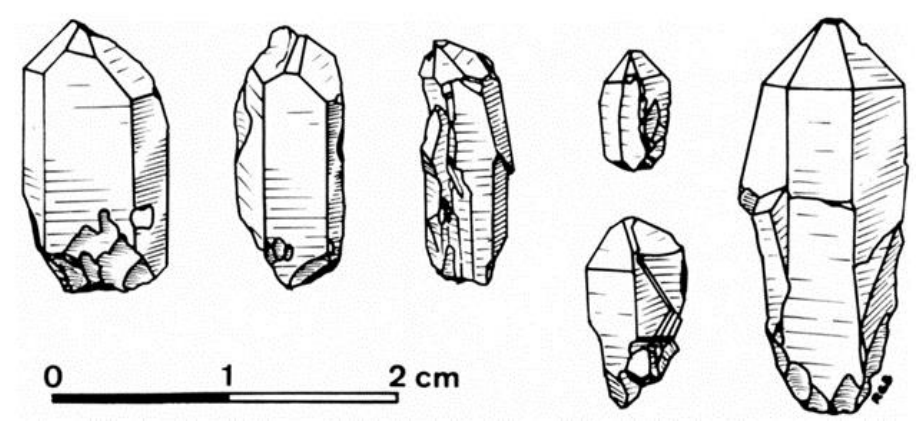

Two petroglyphs excavated in Auditorium Cave, Bhimbetka Site III F-24, Madhya Pradesh in the 1970s (Wakankar 1973, 1975) [149,150] were discovered in 1990 (Bednarik 1992a, 1993b). Reconstruction of the stratigraphy showed that they had been covered by a substantial and well-consolidated, calcite-cemented Middle Palaeolithic deposit that virtually excluded the possibility of post-depositional disturbance, and by the uppermost part of the upper Acheulian layer. They consist of a large circular cupule and a meandering line running parallel to part of its periphery (Figure 19). Their stratigraphical position within the deposit suggests that they were made either in the Acheulian period (Bednarik 1993b, 1994c) [18,23], or in the preceding occupation of the site by hominins using Mode 1-type cobble tools. A few metres from these formerly buried petroglyphs occurs a large standing quartzite slab whose vertical face presents another nine cupules (Figure 20). The co-occurrence at the site of the two buried petroglyphs and the nine cupules above ground suggests that the latter were created at the same time, for the reasons stated in Bednarik (1996b) [26]: they are the only cupules found in the region. Moreover, a great antiquity of the above-ground petroglyphs was confirmed by microerosion analysis. The cave is formed by heavily-metamorphosed quartzite, a rock of such hardness that it was extensively quarried by Acheulian hominins at several Bhimbetka sites. This, 
together with their sheltered location inside a cave, is thought to have facilitated the survival of the Auditorium Cave petroglyphs since the Lower Paleolithic.

Figure 19. Two petroglyphs covered by Acheulian occupation deposit, Auditorium Cave, Bhimbetka rock art complex, central India.

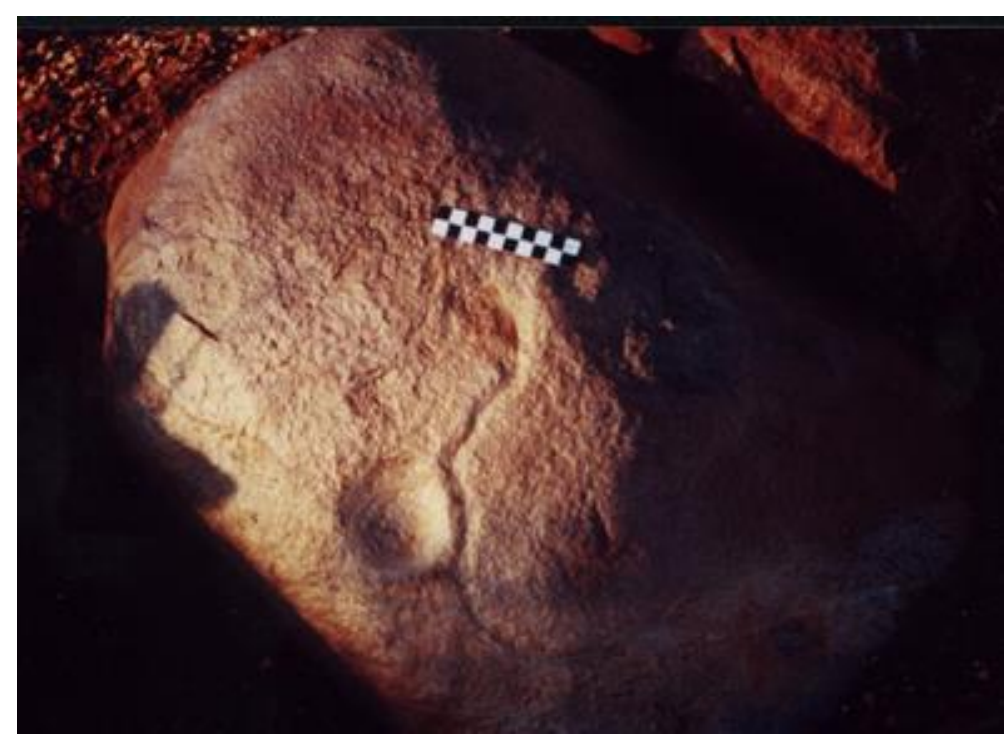

Figure 20. Four of the nine cupules occurring above ground in Auditorium Cave, but also thought to be of the Lower Palaeolithic.

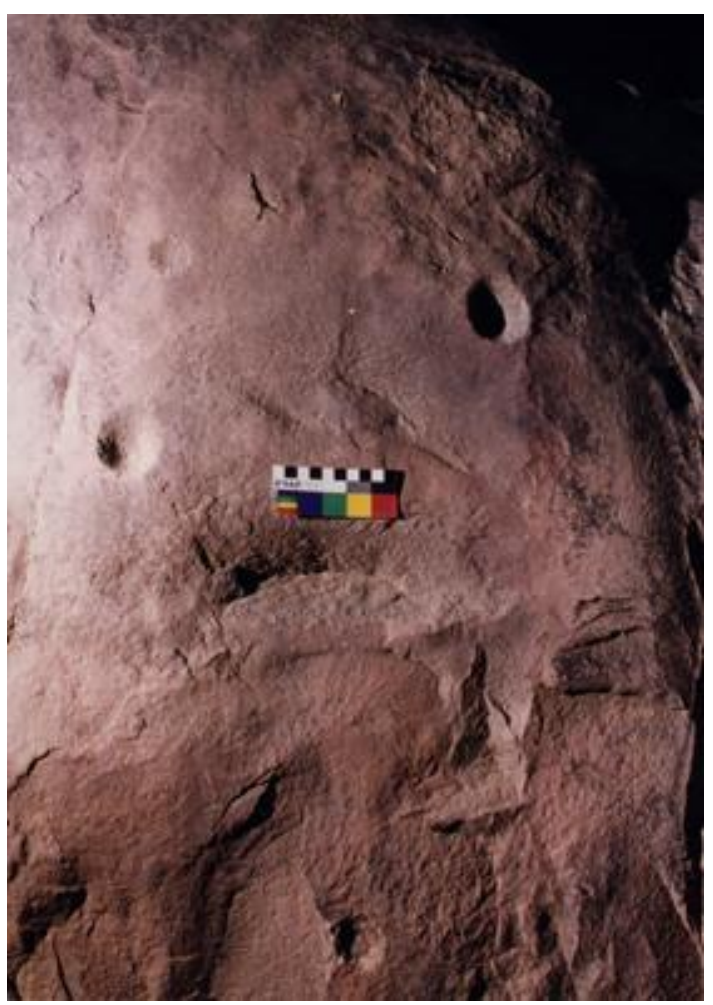

The proposition that the Auditorium petroglyphs are of Lower Palaeolithic age was most audacious at the time, but within a few years found itself well supported by a new discovery. In 1996, another central Indian occurrence of very early petroglyphs was reported, the quartzite cave Daraki-Chattan 
(Kumar 1996) [92]. Because apparently Middle Paleolithic and Acheulian lithics occur on the surface of the cave's floor deposit, it was suggested that the over 500 cupules on its walls might also be of great age (Figure 21). The presence of extensive exfoliation scars at the cave's entrance prompted excavations there, leading to the recovery of numerous exfoliated wall fragments found within the Lower Paleolithic occupation deposit (Bednarik et al. 2005) [45]. These rock slabs bear a total of 28 further cupules, identical to those on the walls above. Also, two engraved grooves were found on a boulder excavated in the Lower Paleolithic deposit, and one cupule was encountered in situ in the excavation. Stone tools exhibiting Lower Paleolithic characteristics occurred both above and together with these slabs, in deposits that are considered undisturbed. Most importantly, hammerstones used in the production of the cupules were recovered below the Acheulian occupation, from the basal deposit containing saprolithised Mode 1 chopping tools that was completely free of bifaces. There can be no reasonable doubt that the cupules, or at least some of them, were made by people of a Lower Paleolithic tool typology dominated by choppers resembling those of the African Oldowan and several Indian sites, and predating the Acheulian.

Figure 21. Some of the over 500 cupules in Daraki-Chattan, at least some of which have been demonstrated to be of a chopping tool industry found below Acheulian deposits; central India.

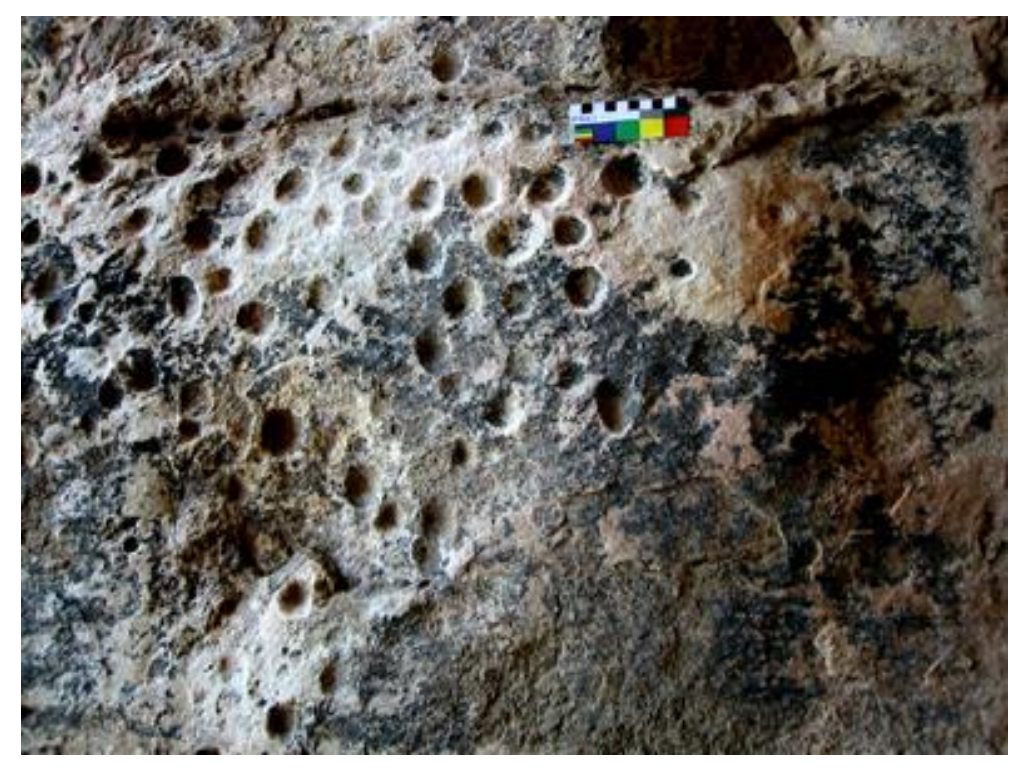

The confirmed Lower Paleolithic petroglyphs of India consist currently of three linear motifs and about 540 cupules. These phenomena form the earliest known rock art of all continents (except Antarctica, where no rock art occurs), as so far no other such petroglyphs have been demonstrated to be of the same great antiquity, based on stone tool typology (Bednarik 2008b) [32]. The earliest cupules of Africa are currently considered to be more recent (Bednarik 2013a; Beaumont and Bednarik 2013) [36,8], while the earliest of Europe date from the Mousterian (Peyrony 1934) [119]. The Acheulian of India has provided further possibly relevant evidence, including two circular, discoid stone objects that seem to be non-utilitarian, one from Bhimbetka III F-24, the other from Maihar (Bednarik 1992a) [13]. 
The Upper Palaeolithic, too, has provided important remains in India, but it should be emphasised that at this stage, no rock art can safely be attributed to that period in India. The only known complex portable palaeoart from the Indian Upper Palaeolithic is an ostrich eggshell fragment from Patne which bears a geometric engraved design (Figure 22). It has been radiocarbon-dated to about $25 \mathrm{ka} \mathrm{BP}$ and the eggshell was not fossil at the time it was engraved. The Upper Palaeolithic bone object from Lohanda Nala, described as a 'mother goddess' or female figurine, is bracketed by radiocarbon dates to between 20,000 and 25,000 years (Misra 1977) [104]. However, it has been shown that it is not a figurine, but a well-made bone harpoon that has suffered extensive damage in its very coarse sediment matrix (Bednarik 1992a, 1993b) [13,18]. Of relevance are also Upper Palaeolithic shell beads from Patne and several perforated discs made from ostrich eggshell (from Bhimbetka and Patne), similar to such Upper Palaeolithic and later beads in other parts of the world (northern China, Mongolia, southern Siberia, Sahara and southern Africa). The fragment of a circular disc of ostrich eggshell with smoothed margin from Nagda is suggested to be of the earliest Upper Palaeolithic. This object is >31 ka old and may thus be Middle Palaeolithic, because that period persisted to about $30 \mathrm{ka}$ BP in India (Kumar et al. 1988) [93]. Finally, the occurrence of animal teeth with grooves to facilitate their attachment to a string has been reported from an Upper Palaeolithic horizon in one of the Kurnool Caves, Billa Surgam III (Bednarik 1993b) [18].

Figure 22. Engraved ostrich eggshell fragment from Patne, western India, c. 25,000 years old.

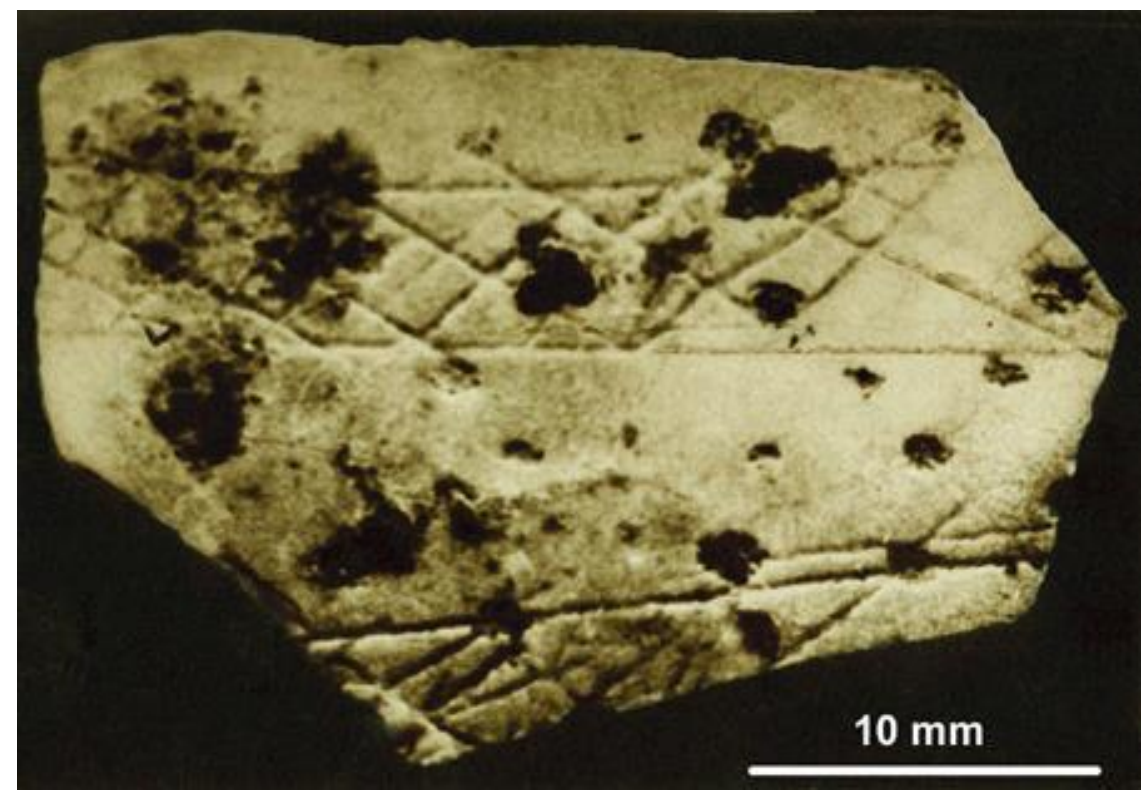

Numerous other claims for Upper Palaeolithic art in India have no credible support. For instance, the grooved patterns on forty-five further ostrich eggshell fragments from a series of six central Indian sites have been shown to be the result of a specific taphonomic process that affects also other mineralised calcareous substances of animal origin, and which has been described in detail (Bednarik 1992d, 1993c) [16,19]. Rock paintings once attributed to the Upper Palaeolithic are now generally considered to be Mesolithic. It is interesting to note that, despite the enormous wealth of apparently Mesolithic rock art in India, there are almost no portable art objects from that period. This tends to corroborate the model involving a massive taphonomic bias. The author has been able to locate only 
six Mesolithic mobiliary art finds in India: the engraved chalcedony core from Chandravati (Sonawane 1991) [130], an engraved human tooth, and four engraved bone fragments. A similarly distorted record also seems to apply to petroglyphs, especially in comparison to the considerable effort in India to record the much more spectacular rock paintings (Bednarik et al. 1991) [44].

In Afghanistan, two pre-Neolithic stone objects have been excavated at Aq Kupruk, but their dating appears uncertain. Marshack (1972) [100], who has examined and reported them, suggests that they may be about 10,000 years old, but there is no certainty of this. One object is an elongate pebble, c. $75 \mathrm{~mm}$ long, which bears an anthropomorphous face, the other is a rectangular small stone tablet, $70 \mathrm{~mm}$ long, clearly scored where it has been broken, bearing four series of regularly spaced notches on some of its edges. While the head-like sculpture seems to be without stylistic parallels, the type of decoration on the tablet can sometimes be found on late Palaeolithic objects, e.g., in Siberia and Russia. Another interesting find from Afghanistan is considerably older, consisting of a fossil shark's tooth at Darra-i-kur which has been reported to have been modified, belonging to a Levallois Mousterian (Dupree 1972: 79) [65]. It provides further evidence that hominins took an interest in fossils they found (Bednarik 1992b) [14].

\section{South-Western Asia}

The known record of Pleistocene art and art-like objects from the Levant seems to mirror this general Asian situation: despite some extremely early clues of non-utilitarian behaviour or exogram production, there is a frustrating paucity of intermediate evidence, and the general impression one gains from the evidence is that it is extremely fragmentary, patchy and taphonomically distorted. There are several indications of very early technological and perhaps cognitive sophistication, including the fragment of a polished plank made from willow wood, between 240,000 and 730,000 years old, the oldest known artefact of its kind (Belitzky et al. 1991) [52]. It comes from the Acheulian deposit of Gesher Benot Ya'aqov, as do two bead-like crinoid fossils with natural central perforations, clearly worn from having been on a string (Figure 23), and a number of very small, angular, unworn quartz crystals (Goren-Inbar et al. 1991) [82]. A scoria pebble with the natural shape of a female torso, head and arms has been found in the Late Acheulian layer of Berekhat Ram (Goren-Inbar 1986) [80], which was sealed between two lava flows dated to 233,000 and 470,000 years respectively (Feraud et al. 1983; Goren-Inbar 1985) [69,79]. Its shape has been emphasised by several deep grooves which the excavator judges to be artificial (Figure 24). The anthropic origin of the object's many markings has been confirmed by two independent examinations (Marshack 1997; d'Errico and Nowell 2000) [101,61]. This is one of only two currently known proto-figurines of the Middle Pleistocene, the other being the Tan-Tan specimen from Morocco, of a similar or somewhat greater age (Bednarik 2013a: Figure 2) [36].

The use of ochre or haematite can be traced back only to the Mousterian in the Levant. For instance, such pigments are present throughout the Mousterian deposits of Qafzeh, Israel, and they include two pieces with burial 8 at that site (Vandermeersch 1981) [146]. At Nahr Ibrahim, Lebanon, the remains of a fallow deer, apparently buried with ochre, have been reported from a Mousterian context (Solecki 1975) [129]. The incised bones recovered from Kebara Cave, Israel, are also of the Mousterian (Davis 1974) [59], and Goren-Inbar (1990) [81] has reported a chert artefact from the Mousterian of Quneitra, Israel, in which natural bedding markings have been deepened, apparently artificially. More 
indubitable is a Middle Palaeolithic Levallois-type core bearing numerous subparallel incisions on one face, from Qafzeh Cave (Hovers et al. 1997) [87]. The Mousterian artefact is $62 \mathrm{~mm}$ long, featuring over twenty grooves, and approximately $100 \mathrm{ka}$ old. A range of other Middle Palaeolithic evidence from the Levant has been described as indicative of some symbolic function (e.g., Leroi-Gourhan 1975, 1989; Bar-Yosef 1989; Belfer-Cohen and Hovers 1992) [95,96,6,51].

Figure 23. Two crinoid fossil casts from the Acheulian of Gesher Benot Ya'aqov, Israel, used as beads, as indicated by the extensive wear on one specimen (after Goren-Inbar et al. 1991).

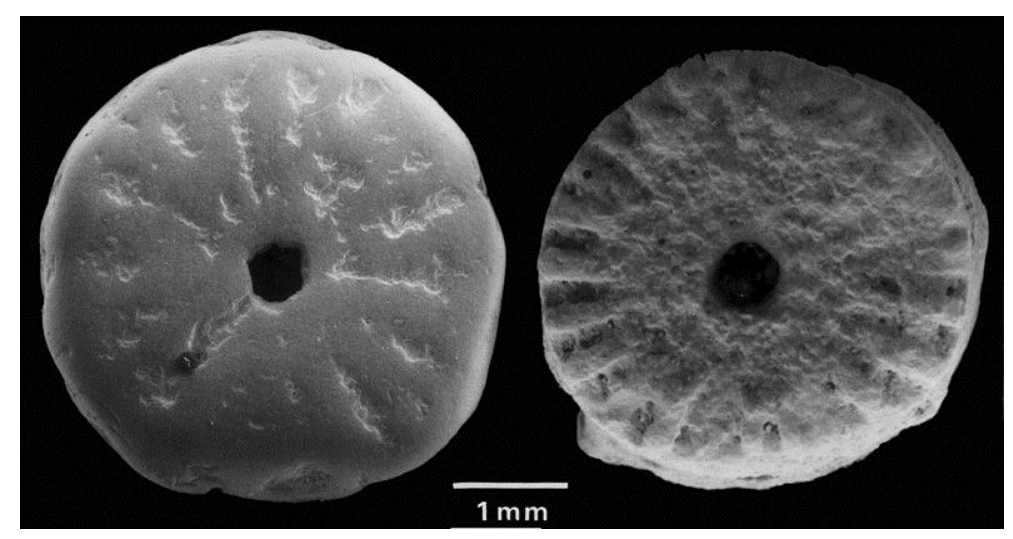

Figure 24. Scoria pebble from the Late Acheulian deposit of Berekhat Ram, Israel, modified by several anthropogenic grooves and abraded areas.

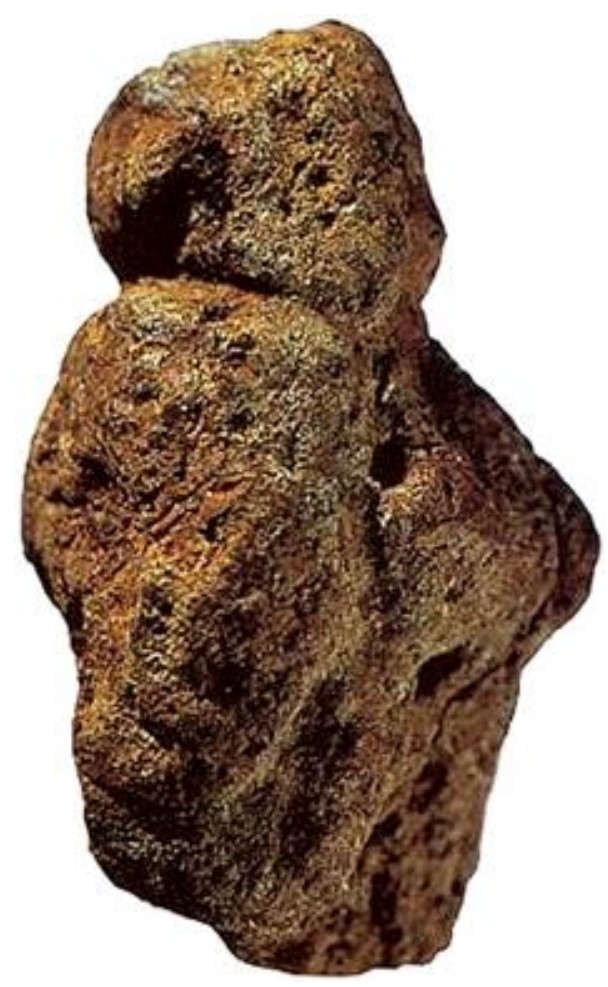

Some linear rock engravings in caves of Mount Carmel have been suggested to be possibly of Palaeolithic age (Ronen and Barton 1981) [124], but the several portable decorated objects from the Upper Palaeolithic provide more reliable evidence, particularly in terms of their approximate age. 
Several items of interest come from the Aurignacian levels of Hayonim Cave, Israel, including a fragment of a bone object with five or six deeply carved parallel grooves across its width; some perforated animal teeth that may have served as pendants or beads; and a limestone slab which bears arrangements of engraved lines on both sides (Belfer-Cohen and Bar-Yosef 1981) [50], in which Bahn (1991) [5] perceives a possible animal figure. More convincing is the limestone cobble from Urkan e-Rub, which is somewhat younger at c. 19-14 ka BP, and is attributed to the Epipalaeolithic (Hovers 1990) [86]. It is also engraved on both sides, bearing complex geometric compositions of arcuate and parallel lines which resemble the marking strategies of other early non-iconic art traditions (Figure 25).

It is only with the Natufian, the Levantine final Pleistocene tradition (c. 12.8-10.3 ka BP), that decorated objects appear in large enough numbers to discern a distinctive 'tradition'. The el-Wad Cave at Mt Carmel features prominently, with art finds first reported back in the 1920s, including figurines, beads, pendants and decorated sickle hafts. A bone sickle haft was carved in the shape of an animal head (Garrod and Bate 1937) [77], there was a human head carved from calcite, and a few 'phallic' objects made of flint nodules (Garrod and Bate 1937: Pls 12, 13) [77]. Other Natufian sites have yielded pestles of 'phallic' shape (Belfer-Cohen 1991; Edwards 1991) [49,66], including Kebara Cave (Turville-Petre 1932: 276) [145], where in addition to several 'phallic' objects an engraved limestone slab was also recovered. A calcite sculpture, apparently of a couple, has been claimed to come from the Early Natufian of Ain Sakhri Cave (Neuville 1951) [110], while a zoomorphic limestone figurine is from the Early Natufian of Wadi Hammeh 27 (Edwards 1991) [66]. Finally, a long bone decorated on both ends was recovered at Nahal Oren (Noy 1991: Figure 5-1) [111]. One end of it has been shaped to resemble an animal head; the other bears a human face in profile.

Figure 25. Epipalaeolithic limestone cobble bearing extensive geometric engraved marks on both sides, from Urkan e-Rub, Israel.

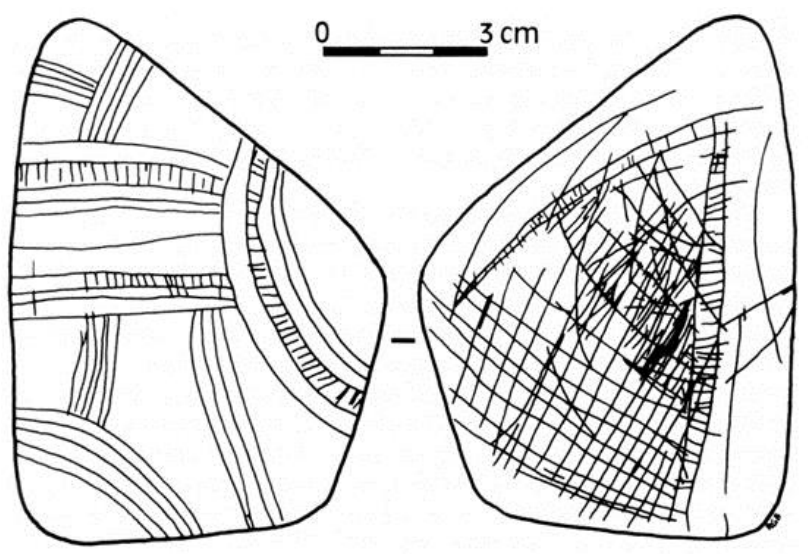

More recent excavations in the el-Wad Cave have provided several new Pleistocene palaeoart finds (Figure 26). This series includes five more objects made of chert nodules and a chert tool that seems to have been shaped into a zoomorphic form (Weinstein-Evron and Belfer-Cohen 1993) [152]. They all bear evidence of rubbing, pitting and incising, and some appear to be again phallic objects. These finds bear no more signs of modification than the Acheulian pebble from Berekhat Ram, but while their authenticity is readily accepted by archaeologists, that of the much older find has long been controversial for some. 
Figure 26. Three of the Natufian modified chert nodules from el-Wad Cave, Israel (after Einstein Evron and Belfer Cohen 1993).

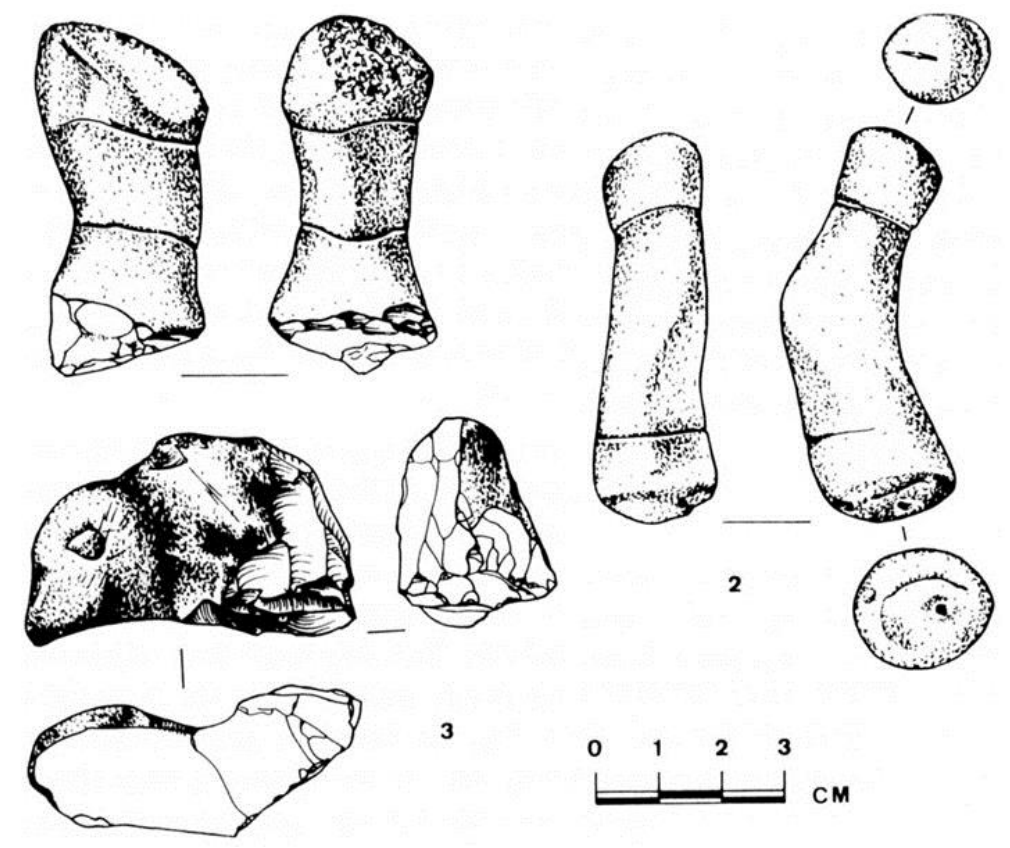

\section{Discussion}

This illuminates a fundamental issue in the epistemology of assessing pre-Upper Palaeolithic evidence suggestive of the use of symbolism. Palaeoart evidence of the Pleistocene is accepted primarily on the basis of age and on how well a find fits into the consensus model (see e.g., Rigaud 2006-2007; Rigaud et al. 2009) [122,123]. This suggests that archaeologists believe that they already know what the cognitive capacities of Palaeolithic people were before they consider all the relevant and available evidence, and that they already know the full range of Pleistocene 'symbolic' production. It is a near-universal aspect of the discipline (cf. Bednarik 1992b) [14] that clashes with scientific perspectives of the cognitive evolution of hominins. The many incommensurabilities between the biosciences and archaeology render it inevitable that the minimalist explanations favoured by archaeology contradict the scientific perspective. They are illustrated by the archaeological perception of evolution as a teleological process, when in fact the sciences see it as a completely dysteleological development. According to Pleistocene archaeology of recent decades, hominins prior to $40 \mathrm{ka}$ ago lacked symboling abilities and therefore probably had no language. This anachronism is neuroscientifically irrational and highly unlikely, given that all hominins and hominids are assumed to have possessed self-awareness, consciousness and theory of mind (Bednarik 2011) [35]. Homology suggests, for instance, that expressions of self-awareness such as body adornment (beads etc.) should be expected to have been used for one or two million years, yet most archaeologists reject all such finds up to the Upper Palaeolithic in Eurasia, and up to $80 \mathrm{ka}$ ago in southern Africa (here in support of the 'African Eve' model). This would imply that the millions of years of continuous encephalisation had severely limited cognitive effects, which in view of its massive evolutionary cost, in obstetric demands (O'Connell et al. 1999) [112] and its burden to society and to the breeding cycle (Joffe 1997; Falk 2009) [88,67] is absurd (Bednarik 2011) [35]. Archaeology's "big bang of consciousness" 
(Klein and Edgar 2002) [90] is supposed to have occurred at the very same time as the significant reduction of brain volume commenced (Bednarik in press) [38]. This "creative explosion" (Pfeiffer 1983; Mithen 1998) [120,108] is perceived at the beginning of a hypothetical period called the Upper Paleolithic, triggering a veritable quantum jump in cognitive and intellectual prowess. The myth attributing the advent of human modernity to the beginning of the Upper Palaeolithic and the arrival of supposedly anatomically modern humans is contradicted by virtually millions of exograms preceding these events, either chronologically or technologically. For instance all of Australia's Pleistocene petroglyphs relate to Middle rather than Upper Palaeolithic technologies, and the world's palaeoart exceeding $40 \mathrm{ka}$ in age (Bednarik 1992b, 2003; Beaumont and Bednarik 2013) [14,29,8] refutes both the "explosion" and the replacement hypothesis it is tied to.

As indicated above there are numerous claims, from most parts of Asia, of rock art being of the Pleistocene, based inevitably on the reasoning that the fauna thought to be depicted is of the Pleistocene. Such contentions are commonly expressed not only in Siberia, as noted, but also in Mongolia, China, South Korea, several of the central Asian republics, occasionally in India, Pakistan, Iran and Azerbaijan. For instance it has been claimed that certain rock art in Arabia dates from the final Pleistocene (by a researcher who has never been there; Anati 1968) [3], but studies of the extensive rock art of Saudi Arabia have provided no support so far. Direct dating places all examined Saudi petroglyphs in the Holocene, and the practice of applying the conditioned alien perception of the modern beholder to the perceived iconographies of the rock artists is a seriously flawed epistemology. Typically authors select from a complex image a few aspects that support their preferred interpretation, claiming them to be diagnostic while ignoring those that overwhelmingly contradict it, or demonstrate that the image as a whole is not naturalistic. Pareidolia is fundamental to the perception of palaeoart by the modern beholder and the process of autosuggestion involved in such 'identifications' (Bednarik 2013b) [37]. Such controversial iconographic pronouncements are not acceptable dating evidence. Direct or scientific age estimations of rock art are so far limited to three Asian countries, China (Qin et al. 1987; Woo 1991; Tang and Gao 2004; Tang and Mei 2008; Tang 2012; Taçon et al. 2012) [121,153,139,140,138,135], Saudi Arabia (Bednarik and Khan 2002, 2005, 2009) [40-42] and India (Bednarik and Kumar 2002; Bednarik et al. 2005; Taçon et al. 2013) [43,45,136]. All of them are limited to the Holocene, but one date from China, as mentioned, is about $11 \mathrm{ka}$. However, the presence of two Lower Palaeolithic cupule sites in India confirms that such exograms were produced in Asia since the Early Pleistocene, which begs the question where the other Ice Age rock art is to be found. There is no shortage of such petroglyphs from Australia, therefore it should have survived out of caves at least in the semi-arid to arid regions of Asia.

The picture emerging from these considerations is that the known (and probably authentic) panAsian Pleistocene rock art and portable palaeoart suggests that the published examples, though quite numerous from some regions, overall represent a severely distorted sample. Not only has the surviving corpus no doubt experienced significant taphonomic reduction through differential preservation, the bias against finding such remains, recognising them and having them reported 'effectively' are at least as significant. The known sample reviewed here should therefore not be considered without an appreciation of the factors that have contributed to the distortion of this 'archaeological record'. For instance, there is evidence from several Asian countries that local researchers, in trying to locate Pleistocene art, have been guided by western European models of what such material should be. It was 
perceived that western European Palaeolithic art is generally 'naturalistic' (because of the distorted way it had been reported), and predominantly of large animals and of female humans. Specific 'stylistic' elements of the Franco-Cantabrian iconic art that had been subjectively identified by western European researchers have guided Asian researchers in their quest to find Pleistocene art. By the same token, art that did not fit the European mould was ignored, or regarded as somehow 'inferior'. These severe research biases have distorted the record at least as much as aspects of preservation.

Another major factor has been the significant disparity in research intensity across the continent. It is obvious that the only two concentrations of Pleistocene palaeoart known in Asia are from the two geographical regions that have seen the most sustained research efforts: the Levant and the region near Irkutsk. This can hardly be a coincidence when it is considered that, in various parts of Asia, almost no Pleistocene research has ever been conducted. In countries such as China and India, early palaeoart clearly does exist, but the number of confirmed instances is incredibly minute, yet it includes the oldest currently known rock art in the world. These isolated, tantalising clues confirm that what we know of Asian Pleistocene art is extremely tenuous, isolated and no doubt unrepresentative. It is therefore inappropriate to attempt any form of synthesis on the basis of the available remnant sample, which provides certainly no adequate data for any distributional or compositional interpretation of the available evidence. Despite these significant reservations, which mirror those applying to Africa, some very tentative deductions will be attempted here, which seem possible especially if the sparse evidence is placed into a global context of archaic 'art' systems (Bednarik 1994c) [23].

The most pervasive characteristic of the very limited Pleistocene palaeoart from Asia is the almost complete absence of two-dimensional (graphic) figurative depiction. This is not at all surprising, because the same situation pertains to eastern Europe and Africa: nearly all of the world's known Pleistocene figurative graphic depictions are from western Europe, whereas the graphic Ice Age art of the rest of the world is almost entirely non-figurative, as far as we can tell (Bednarik 1993d) [20]. Even in western Europe, an estimated more than three-quarters of the graphic art is non-figurative, but there the figurative component has been over-emphasised in most reports.

Three-dimensional figurative art may have a much longer history, however. The animated Tolbaga animal head has its counterparts in the similarly sophisticated sculpted art of central Europe (southern Germany and Austria, between 40 and 30 ka old). The Berekhat Ram find may remain isolated, with only a single parallel from Africa, but there are a number of indications that the iconicity of natural shapes was recognised quite early, and that sculpture began by emphasising the iconic features of natural forms. These practices continued right to the end of the Pleistocene, as shown by the Natufian of the Levant. The extremely early petroglyphs of Bhimbetka have their counterparts in the cupules of one French Mousterian site and in several South African locations. Another notable consistency is suggested by the earliest forms of apparent non-utilitarian behaviour, especially the use of haematite and quartz crystals. Certainly the type of evidence found is the result of taphonomic biases, but these are also universal, and such finds occur in the Acheulian of Africa and Europe as well (Bednarik 1992b, 1994c, 2003) [14,23,29]. Similarly, in China, Japan and Russia, the earliest known art-like evidence includes artificially perforated flat pebbles, probably used as pendants, i.e., a taphonomically highly resistant class of object. Perhaps these observations do indicate some underlying patterns, even if they do not suffice to form a Eurasian synthesis of Pleistocene palaeoart development. Such patterns 
seem to indicate much more uniformity than more regional comparisons, or a superficial comparison between Asian and European Pleistocene evidence, might suggest.

The impression one gains from the present review is that the general progression of art development across the Old World was relatively homogenous. In such a broadly based model it is also essential to consider the roles of the Americas and Australia (Bednarik 1994c, 2010) [23,34], because it is almost universally assumed that all three continents were initially settled from Asia. It is now almost certain that they were first peopled by hominins who possessed the capability of symbolic expression. There is a particularly well-preserved corpus of Pleistocene rock art in Australia, many times the size of that of Europe, which has also attracted almost no attention. Asia, therefore, not only occupies the geographically central position in hominin expansion, but perhaps also an important position in Pleistocene 'art' development. The arrant neglect of Asian palaeoart until now has had a serious effect on all models of this development. Without exception, they can be safely regarded as irrelevant to a universal paradigm, as they are based on inadequate data for such a purpose. The effects of this distortion can be easily appreciated by considering the following parallel: most European Pleistocene archaeologists see bone harpoons as an invention of the people they call Magdalenians. This notion came into existence because there are very few much older specimens, but they do nevertheless exist, showing that this artefact has a long history: in Africa there are the examples from Katanda, Zaire (Brooks et al. 1995) [54]; the bone harpoon from Lohanda Nala, India (Bednarik 1995) [24] has been mentioned; and the probably much older one from Solo River, Java (Narr 1966: 123) [109]. Ignoring these finds in the context of a study of early harpoons is like ignoring the massive evidence of extraEuropean Pleistocene palaeoart. It can only yield a hopelessly skewed view of the cultural development of hominins, and this paper has tried to make a small contribution to correcting this state.

\section{Conflict of Interest}

The author declares no conflict of interest.

\section{References}

1. Abramova, Z.A. L'art mobilier paléolithique en Siberie. Boll. Centro Camuno Studi Preist. 1990, 25/26, 80-98.

2. Aikens, C.M.; Higuchi, T. Prehistory of Japan; Academic Press: London, UK and New York, NY, USA, 1982.

3. Anati, E. Rock Art in Central Arabia, 2 vols. Bibliothèque du Muséon, Vol. 50. Institut Orientaliste Bibliothèque de l'Universite, Louvain, Belgium, 1968.

4. Aung, Y.Y. New discoveries of rock art in Badalin Caves, Myanmar. Rock Art Res. 2013, 30, 253.

5. Bahn, P.G. Pleistocene images outside Europe. Proc. Prehist. Soc. 1991, 57, 91-102.

6. Bar-Yosef, O. Upper Pleistocene Cultural Stratigraphy in Southeast Asia. In The Emergence of Modern Humans; Trinkaus, E., Ed.; Cambridge University Press: Cambridge, UK, 1989; pp. 154-180.

7. Beaumont, P.B. The edge: More on fire-making by about 1.7 million years ago at Wonderwerk Cave in South Africa. Curr. Anthropol. 2011, 52, 585-595. 
8. Beaumont, P.B.; Bednarik, R.G. Tracing the emergence of palaeoart in sub-Saharan Africa. Rock Art Res. 2013, 30, 33-54.

9. Bednarik, R.G. Engramme und Phosphene. Z. Ethnol. 1987, 112, 223-235.

10. Bednarik, R.G. The Galgenberg figurine from Krems, Austria. Rock Art Res. 1989, 6, 118-125.

11. Bednarik, R.G. More to Palaeolithic females than meets the eye. Rock Art Res. 1990, 7, 133-137.

12. Bednarik, R.G. An Acheulian haematite pebble with striations. Rock Art Res. 1990, 7, 75.

13. Bednarik, R.G. The Paleolithic Art of Asia. In Ancient images, ancient thought: The archaeology of ideology, Goldsmith, S., Garvie, S., Selin, D., Smith, J., Eds.; University of Calgary: Calgary, Canada, 1992; pp. 383-390.

14. Bednarik, R.G. Palaeoart and archaeological myths. Camb. Archaeol. J. 1992, 2, 27-43.

15. Bednarik, R.G. Palaeolithic art found in China. Nature 1992, 356, 116.

16. Bednarik, R.G. Natural line markings on Palaeolithic objects. Anthropologie 1992, 29, 233-240.

17. Bednarik, R.G. Pleistocene animal depiction in Asia. Int. Newsl. Rock Art 1993, 6, 2-6.

18. Bednarik, R.G. Palaeolithic art in India. Man Environ. 1993, 18, 33-40.

19. Bednarik, R.G. About Palaeolithic ostrich eggshell in India. Indo-Pacific Prehist. Assoc. Bull. 1993, 13, 34-43.

20. Bednarik, R.G. European Palaeolithic art-Typical or exceptional? Oxf. J. Archaeol. 1993, 12, $1-8$.

21. Bednarik, R.G. The Pleistocene art of Asia. J. World Prehist. 1994, 8, 351-375.

22. Bednarik, R.G. A taphonomy of palaeoart. Antiquity 1994, 68, 68-74.

23. Bednarik, R.G. Art origins. Anthropos 1994, 89, 169-180.

24. Bednarik, R.G. Challenge posed by the Palaeolithic art of Asia (in Chinese). Yan Hua (Rock Art) 1995, 1, 17-21.

25. Bednarik, R.G. Palaeolithic love goddesses of feminism. Anthropos 1996, 91, 183-190.

26. Bednarik, R.G. The cupules on Chief's Rock, Auditorium Cave, Bhimbetka. Artefact 1996, 19, 63-72.

27. Bednarik, R.G. The role of Pleistocene beads in documenting hominid cognition. Rock Art Res. 1997, 14, 27-41.

28. Bednarik, R.G. The 'austrolopithecine' cobble from Makapansgat, South Africa. S. Afr. Archaeol. Bull. 1998, 53, 4-8.

29. Bednarik, R.G. The earliest evidence of palaeoart. Rock Art Res. 2003, 20, 89-135.

30. Bednarik, R.G. Middle Pleistocene beads and symbolism. Anthropos 2005, 100, 537-552.

31. Bednarik, R.G. Beads and the origins of symbolism. Time Mind J. Archaeol. Conscious. Cult. 2008, 1, 285-318.

32. Bednarik, R.G. Cupules. Rock Art Res. 2008, 25, 61-100.

33. Bednarik, R.G. Fluvial erosion of inscriptions and petroglyphs at Siega Verde, Spain. J. Archaeol. Sci. 2009, 36, 2365-2373.

34. Bednarik, R.G. Pleistocene rock art in Australia. Anthropos 2010, 105, 3-12.

35. Bednarik, R.G. The Human Condition; Springer: New York, NY, USA, 2011.

36. Bednarik, R.G. Pleistocene palaeoart of Africa. Special issue 'World rock art'. Arts 2013, 2, 6-34.

37. Bednarik, R.G. Megafauna depictions in Australian rock art. Rock Art Res. 2013, 30, 197-215. 
38. Bednarik, R.G. Doing with less: Hominin brain atrophy. Curr. Anthropol. In press.

39. Bednarik, R.G.; Devlet, K. Rock art conservation in Siberia. Purakala 1992, 3, 311.

40. Bednarik, R.G.; Khan, M. The Saudi Arabian rock art mission of November 2001. Atlal 2002, 17, 75-99.

41. Bednarik, R.G.; Khan, M. Scientific studies of Saudi Arabian rock art. Rock Art Res. 2005, 22, 49-81.

42. Bednarik, R.G.; Khan, M. The rock art of southern Arabia reconsidered. Adumatu Journal 2009, 20, 7-20.

43. Bednarik, R.G.; Kumar, G. The quartz cupules of Ajmer, Rajasthan. Purakala 2002, 13, 45-50.

44. Bednarik, R.G.; Kumar, G.; Tyagi, G.S. Petroglyphs from central India. Rock Art Res. 1991, 8, 33-35.

45. Bednarik, R.G.; Kumar, G.; Watchman, A.; Roberts, R.G. Preliminary results of the EIP Project. Rock Art Res. 2005, 22, 147-197.

46. Bednarik, R.G.; Fushun, L. Rock art dating in China: Past and future. Artefact 1991, 14, $25-33$.

47. Bednarik, R.G.; Sreenathan, M. Traces of the ancients: Ethnographic vestiges of Pleistocene 'art'. Rock Art Res. 2012, 29, 191-217.

48. Bednarik, R.G.; Yuzhu, Y. Palaeolithic art from China. Rock Art Res. 1991, 8, 119-123.

49. Belfer-Cohen, A. The Natufian in the Levant. Annu. Rev. Anthropol. 1991, 20, 167-186.

50. Belfer-Cohen, A.; Bar-Yosef, O. The Aurignacian at Hayonim Cave. Paléorient 1981, 7, 19-42.

51. Belfer-Cohen, A.; Hovers, E. In the eye of the beholder: Mousterian and Natufian burials in the Levant. Curr. Anthropol. 1992, 33, 463-471.

52. Belitzky, S.; Goren-Inbar, N.; Werker, E. A Middle Pleistocene wooden plank with man-made polish. J. Hum. Evol. 1991, 20, 349-353.

53. Boriskovski, P.I. Paleolit SSSR; Izdatel'stvo Nauka: Moscow, Russia, 1984.

54. Brooks, A.S.; Helgren, D.M.; Cramer, J.S.; Franklin, A.; Hornyak, W.; Keating, J.M.; Klein, R.G.; Rink, W.J.; Schwarcz, H.; Smith, J.N.L.; et al. Dating and context of three Middle Stone Age sites with bone points in the Upper Semliki valley, Zaire. Science 1995, 268, $548-553$.

55. Butti, C.; Sherwood, C.C.; Hakeem, A.Y.; Allman, J.M. Total number and volume of von Economo neurons in the cerebral cortex of cetaceans. J. Comp. Neurol. 2009, 515, 243-259.

56. Chen, T.M.; Yuan, S.X.; Gao, S.J. The study on uranium-series dating of fossil bones and an absolute age sequence for the main Palaeolithic sites of north China (in Chinese). Acta Anthropol. Sin. 1984, 3, 259-269.

57. Chen, Z.F. History of the Discovery of Chinese Rock Art; Shanghai People's Publishing House: Shanghai, China, 1991; (in Chinese).

58. Christian, K.M.; Thompson, R.F. Long-term storage of an associative memory trace in the cerebellum. Behav. Neurosci. 2005, 119, 256-537.

59. Davis, S.J.M. Incised bones from the Mousterian of Kebara Cave (Mount Carmel) and the Aurignacian of Ha-yonim (Western Galilee), Israel. Paléorient 1974, 2, 181-182.

60. D'Errico, F.; Gaillard, C.; Misra, V.N. Collection of non-utilitarian objects by Homo erectus in India. Hominidae. In Proceedings of the 2nd International Congress of Human Paleontology, Editoriale Jaca Book, Milan, 1989; pp. 237-239. 
61. D'Errico, F.; Nowell, A. A new look at the Berekhat Ram figurine: Implications for the origins of symbolism. Camb. Archaeol. J. 2000, 10, 123-167.

62. De Veer, M.W.; van den Bos, R. A critical review of methodology and interpretation of mirror self-recognition research in nonhuman primates. Anim. Behav. 1999, 58, 459-468.

63. Dobres, M.-A. Re-considering Venus Figurines: A Feminist-inspired Re-analysis. In Ancient Images, Ancient Thought: The Archaeology of Ideology; Goldsmith, A.S., Garvie, S., Selin, D., Smith, J., Eds.; 1992; pp. 245-262. Proceedings of the 23rd Annual Chacmool Conference, University of Calgary, Calgary, Canada.

64. Duhard, J.-P. La posture des mains pendant la grossesse. Rock Art Res. 1990, 7, 137-140.

65. Dupree, L. Tentative Conclusions and Tentative Chronological Charts. In L. Dupree (ed.), Prehistoric Research in Afghanistan (1959-66). Transactions of the American Philosophical Society 1972, 62, 74-82.

66. Edwards, P. Wadi Hammeh 27: An Early Natufian Site at Pella, Jordan. In The Natufian Culture in the Levant, International Monographs in Prehistory; Bar-Yosef, O., Valla, F., Eds.; University of Michigan, Ann Arbor, MI, USA, 1991; pp. 123-148.

67. Falk, D. Finding our Tongues: Mothers, Infants and the Origins of Language; Basic Books: New York, NY, USA, 2009.

68. Peng, F.; Gao, X.; Wang, H.M.; Chen, F.Y.; Liu, D.C.; Pei, S.W. An engraved artifact from Shuidonggou, an Early Late Paleolithic Site in Northwest China. Chin. Sci. Bull. 2012, 57, 4594-4599.

69. Feraud, G.; York, D.; Hall, C.M.; Goren-Inbar, N.; Schwarcz, H.P. ${ }^{40} \mathrm{Ar} /{ }^{39} \mathrm{Ar}$ age limit for an Acheulean site in Israel. Nature 1983, 304, 263-265.

70. Gai, S. Petroglyphs in the Yinshan Mountains; Cultural Relics Publishing House: Beijing, China, 1986.

71. Gaillard, C. Les premiers peuplements d'Asie du sud: Vestiges culturels. Comptes Rendus Palevol 2006, 5, 359-369.

72. Gaillard, C.; Raju, D.R.; Misra, V.N.; Rajaguru, S.N. Acheulian occupation at Singi Talav in the Thar Desert, India: A preliminary report on 1982 excavation. Man Environ. 1983, 7, 112-130.

73. Gallup, G.G., Jr. Chimpanzees: Self recognition. Science 1970, 167, 86-87.

74. Gallup, G.G., Jr. Self-awareness and the evolution of social intelligence. Behav. Processes 1998, 42, 239-247.

75. Gallup, G.G., Jr.; Anderson, J.L.; Shillito, D.P. The Mirror Test. In The Cognitive Animal: Empirical and Theoretical Perspectives on Animal Cognition; Bekoff, M., Allen, C., Burghardt, G.M., Eds.; University of Chicago Press: Chicago, IL, USA, 2002; pp. 325-333.

76. Gao, X.; Huang, W.; Xu, Z.; Ma, Z.; Olsen, J.W. 120-150 ka human tooth and ivory engravings from Xinglongdong Cave, Three Gorges region, south China. Chin. Sci. Bull. 2004, 49, 175-180.

77. Garrod, D.A.E.; Bate, D.M.A. The Stone Age of Mount Carmel; Claredon Press: Oxford, UK, 1937; Volume I.

78. Gimbutas, M. Civilization of the Goddess; Harper: San Francisco, CA, USA, 1991.

79. Goren-Inbar, N. The lithic assemblages of Berekhat Ram Acheulean site, Golan Heights. Paléorient 1985, 11, 7-28. 
80. Goren-Inbar, N. A figurine from the Acheulian site of Berekhat Ram. Mi'Tekufat Ha'Even 1986, 19, 7-12.

81. Goren-Inbar, N. Quneitra: A Mousterian Site on the Golan Heights; Monograph 31, Institute of Archaeology: Jerusalem, CA, USA, 1990.

82. Goren-Inbar, N.; Lewy, Z.; Kislev, M.E. The taphonomy of a bead-like fossil from the Acheulian of Gesher Benot Ya'aqov, Israel. Rock Art Res. 1991, 8, 83-87.

83. Gvozdover, M.D. The typology of female figurines of the Kostenki Palaeolithic culture. Sov. Anthropol. Archaeol. 1989, 27, 32-94.

84. Hakeem, A.Y.; Sherwood, C.C.; Bonar, C.J.; Butti, C.; Hof, P.R.; Allman, J.M. Von Economo neurons in the elephant brain. Anat. Record 2009, 292, 242-248.

85. Heyes, C.M. Theory of mind in nonhuman primates. Behav. Brain Sci. 1998, 21, 101-134.

86. Hovers, E. Art in the Levantine Epi-Palaeolithic: An engraved pebble from a Kebaran site in the lower Jordan valley. Curr. Anthropol. 1990, 31, 317-322.

87. Hovers, E.; Vandermeersch, B.; Bar-Yosef, O. A Middle Palaeolithic engraved artefact from Qafzeh Cave, Israel. Rock Art Res. 1997, 14, 79-87.

88. Joffe, T.H. Social pressures have selected for an extended juvenile period in primates. J. Hum. Evol. 1997, 32, 593-605.

89. Keenan, J.P.; Falk, D.; Gallup, G.C., Jr. The Face in the Mirror: The Search for the Origins of Consciousness; Harper Collins Publishers: New York, NY, USA, 2003.

90. Klein, R.G.; Edgar, B. The Dawn of Human Culture: A Bold New Theory on What Sparked the "Big Bang” of Human Consciousness; Wiley \& Sons: New York, NY, USA, 2002.

91. Krause, J.; Fu, Q.; Good, J.M.; Viola, B.; Shunkov, M.V.; Derevianko, A.P.; Pääbo, S. The complete mitochondrial DNA genome of an unknown hominin from southern Siberia. Nature 2010, 464, 894-897.

92. Kumar, G. Daraki-Chattan: A Palaeolithic cupule site in India. Rock Art Res. 1996, 13, 38-46.

93. Kumar, G.; Narvare, G.; Pancholi, R. Engraved ostrich eggshell objects: New evidence of Upper Palaeolithic art in India. Rock Art Res. 1988, 5, 43-53.

94. Lashley, K.S. In search of the engram. Soc. Exp. Biol. 1950, 4, 454-482.

95. Leroi-Gourhan, A. The flowers found with Shanidar IV, a Neanderthal burial in Iraq. Science 1975, 190, 562-565.

96. Leroi-Gourhan, A. Comment. Curr. Anthropol. 1989, 30, 183.

97. Li, F. A survey on the methods of dating rock art in China. Int. Newsl. Rock Art 1992, 2, 15-20.

98. Liu, D.C.; Wang, X.L.; Gao, X.; et al. Progress in the stratigraphy and geochronology of the Shuidonggou site, Ningxia, north China. Chin. Sci. Bull. 2009, 54, 3880-3886.

99. Liu, Y. New discovery and historical division of the petroglyphs in Helan Mountains. Paper Presented at the International Conference of Rock Art Study, Recording and Conservation, Yinchuan, China, 1991.

100. Marshack, A. Aq Kupruk: Art and symbol. Trans. Am. Philos. Soc. 1972, 62, 66-72, 83-84.

101. Marshack, A. The Berekhat Ram figurine: A late Acheulian carving from the Middle East. Antiquity 1997, 71, 327-337.

102. McGrew, W.C. The Cultured Chimpanzee; Cambridge University Press: Cambridge, UK, 2004. 
103. McGrew, W.C.; Marchant, L.F. Chimpanzee wears a knotted skin 'necklace'. Pan Afr. News 1998, 5, 8-9.

104. Misra, V.D. Some Aspects of Indian Archaeology; Prabhat Prakashan: Allahabad, India, 1977.

105. Mitchell, R.W. Mental models of mirror-self-recognition: Two theories. New Ideas Psychol. 1993, 11, 295-325.

106. Mitchell, R.W. Kinesthetic-visual matching and the self-concept as explanations of mirror-self-recognition. J. Theory Soc. Behav. 1997, 27, 18-39.

107. Mitchell, R.W. Subjectivity and Self-recognition in Animals. In Handbook of Self and Identity; Leary, M.R., Tangney, J.P., Eds.; Guilford Press: New York, NY, USA, 2002; pp. 567-595.

108. Mithen, S. Creativity in Human Evolution and Prehistory; Routledge: New York, NY, USA, 1998.

109. Narr, K.J. Die Frühe und Mittlere Altsteinzeit Süd- und Ostasiens. In Handbuch der Urgeschichte, Vol. 1, Ältere und Mittlere Steinzeit: Jäger- und Sammlerkulturem; Narr, K.J., Ed.; Francke Verlag: Berne and Munich, Switzerland/Germany, 1966; pp. 113-133.

110. Neuville, R. Le Paléolithique et le Msolithique du désert de Judée. Archives de l'Institut de Paléontologie Humaine. Masson, Paris, France, 1951.

111. Noy, T. Art and decoration of the Natufian at Nahal Oren. In The Natufian Culture in the Levant; Bar-Yosef, O., Valla, F.R., Eds.; International Monographs in Prehistory: Ann Arbor, MI, USA, 1991; pp. 557-568.

112. O’Connell, J.F.; Hawkes, K.; Jones, N.G.B. Grandmothering and the evolution of Homo erectus. J. Hum. Evol. 1999, 36, 461-485.

113. Okamura, M. The achievements of research into the Japanese Palaeolithic. Acta Asiat. 1992, 63, 21-39.

114. Okladnikov, A.P. Shishkinsie Pisanitsi; Irkutsk: Russia, 1959.

115. Okladnikov, A.P. Petroglify Verkhnei Leny; Izdatel'stvo 'Nauka': Leningrad, Russia, 1977.

116. Okladnikov, A.P.; Saporoshskaya, W.D. Lenskije Pissanizy; Izdatel'stvo Academii Nauk SSSR, Moscow/Leningrad, Russia, 1959.

117. Paddayya, K. The Acheulian Culture of the Hunsgi Valley, Peninsular India: A Settlement System Perspective; Deccan College: Pune, India, 1982.

118. Pei, W.C. Notice of the discovery of quartz and other stone artifacts in the Lower Pleistocene hominid-bearing sediments of the Choukoutien Cave deposits. Bull. Geol. Soc. China 1931, 11, 109-146.

119. Peyrony, D. La Ferrassie. Moustérien, Périgordien, Aurignacien. Préhistoire 1934, 3, 1-92.

120. Pfeiffer, J.E. The Creative Explosion: An Inquiry into the Origins of Art and Religion; Harper \& Row: New York, NY, USA, 1983.

121. Qin, S.; Qin, T.; Lu, M.; Yü, J. The Investigation and Research of the Cliff and Mural Paintings of the Zuojiang River Valley in Guangxi; Guangxi National Printing House: Nanning, China, 1987.

122. Rigaud, S. Révision critique des Porosphaera globularis interprétées comme éléments de parure acheuléens. Unpublished Masters Thesis, Université Bordeaux 1, France, 2006-2007.

123. Rigaud, S.; d'Errico, F.; Vanhaeren, M.; Neumann, C. Critical reassessment of putative Acheulean Prosphaere globularis beads. J. Archaeol. Sci. 2009, 36, 25-34. 
124. Ronen, A.; Barton, G.M. Rock engravings on western Mount Carmel, Israel. Quartär 1981, 31/32, 121-137.

125. Russell, P. Learning from curves: The female figure in Palaeolithic Europe. Rock Art Res. 2006, $23,41-49$.

126. Seeley, W.W.; Carlin, D.A.; Allman, J.M. Early frontotemporal dementia targets neurons unique to apes and humans. Ann. Neurol. 2006, 60, 660-667.

127. Sohn, P.-K. Palaeolithic culture of Korea. Korea J. 1974, 14, 4-11.

128. Sohn, P.-K. Inception of Art Mobilier in the Middle Palaeolithic period at Chommal Cave, Korea. In Resumenes de Comunicaciones, Paleolítico Medio; Xth UISPP Congress, Mexico City, Mexio, 1981; pp. 31-32.

129. Solecki, R. The Middle Palaeolithic site of Nahr Ibrahim (Asfurieh Cave) in Lebanon. In Problems in Prehistory: North Africa and the Levant; Wendorf, F., Marks, A., Eds.; Southern Methodist University Press: Dallas, USA, 1975; pp. 283-295.

130. Sonawane, V.H. An Engraved Mesolithic Core from Chandravati, Rajasthan. In Archaeology and History: Essays in Memory of Shri A. Ghosh; Pande, P.M., Chattopadhaya, B.D., Eds.; Agam Kala Prakashan, Delhi, India, 1991; Volume I, pp. 53-56.

131. Steelman, K.L.; Rowe, M.W.; Shirokov, V.N.; Southon, J.R. Radiocarbon dates for pictographs in Ignatievskaya Cave, Russia: Holocene age for supposed Pleistocene fauna. Antiquity 2002, 76, 341-348.

132. Steinmetz, J.E.; Lavond, D.G.; Ivkovich, D.; Logan, C.G.; Thompson, R.F. Disruption of classical eyelid conditioning after cerebellar lesions: Damage to a memory trace system or a simple performance deficit? J. Neurosci. 1992, 12, 4403-4426.

133. Steinmetz, J.E.; Logan, C.G.; Rosen, D.J.; Thompson, J.K.; Lavond, D.G.; Thompson, R.F. Initial localization of the acoustic conditioned stimulus projection system to the cerebellum essential for classical eyelid conditioning. Proc. Natl. Acad. Sci. USA 1987, 84, 3531-3535.

134. Steinmetz, J.E.; Thompson, R.F. Brain Substrates of Aversive Classical Conditioning. In Neurobiology of Learning, Emotion and Affect; Madden, J., Ed.; Raven Press, New York, NY, USA, 1991; pp. 97-120.

135. Taçon, P.S.C.; Aubert, M.; Li, G.; Yang, D.; Liu, H.; May, S.K.; Fallon, S.; Ji, X.; Curnoe, D.; Herries, A.I.R. Uranium-series age estimates for rock art in southwest China. J. Archaeol. Sci. 2012, 39, 492-499.

136. Taçon, P.S.C.; Boivin, N.; Petraglia, M.; Blinkhorn, J.; Chivas, A.; Roberts, R.G.; Fink, D.; Higham, T.; Ditchfield, P.; Korisettar, R.; Zhao, J.-X. Mid-Holocene age obtained for nested diamond pattern petroglyph in the Billasurgam Cave complex, Kurnool District, southern India. J. Archaeol. Sci. 2013, 40, 1787-1796.

137. Tang, H. Theory and methods in Chinese rock art studies. Rock Art Res. 1993, 10, 83-90.

138. Tang, H. New discovery of rock art and megalithic sites in the Central Plain of China. Rock Art Res. 2012, 29, 157-170.

139. Tang, H.; Gao, Z. Dating analysis of rock art in the Qinghai-Tibetan Plateau. Rock Art Res. 2004, 21, 161-172.

140. Tang, H.; Mei, Y. A discussion on the date of prehistoric petroglyphs from the Jiangjunya site. Southeast Cult. 2008, 202, 11-23. 
141. Thompson, R.F. Foundations of Physiological Psychology; Harper \& Row: New York, NY, USA, 1967.

142. Thompson, R.F. The neurobiology of learning and memory. Science 1986, 233, 941-947.

143. Thompson, R.F. Neural mechanisms of classical conditioning in mammals. Philos. Trans. R. Soc. Lond. B 1990, 329, 161-170.

144. Thompson, R.F.; Berger, T.W.; Cegavske, C.F.; Patterson, M.M.; Roemer, R.A.; Teyler, T.J.; Young, R.A. The search for the engram. Am. Psychol. 1976, 31, 209-227.

145. Turville-Petre, F. Excavations in the Mugharet el-Kebarah. J. R. Anthropol. Inst. 1932, 62, 271-276.

146. Vandermeersch, B. Les Hommes Fossiles de Qafzeh (Israël); Centre national de la recherche scientifique, Paris, France, 1981.

147. Vartanyan, S.L.; Garutt, V.E.; Sher, A.V. Holocene dwarf mammoths from Wrangel Island in the Siberian Arctic. Nature 1993, 362, 337-340.

148. Vasilevski, R.S.; Drozdov, N.I. Paleoliticheskie Skulpturnye Izobrazhenia iz Vostochnoi Sibiri. Plastika i Risunki Drevnikh Kultur; Novosibirsk: Russia, 1983; pp. 59-65.

149. Wakankar, V.S. Bhimbetka excavations. J. Indian Hist. 1973, 51, $23-33$.

150. Wakankar, V.S. Bhimbetka-The prehistoric paradise. Prachya Pratibha 1975, 3, 7-29.

151. Wang, N. An introduction to rock paintings in Yunnan Province (People's Republic of China). Rock Art Res. 1984, 1, 75-90.

152. Weinstein-Evron, M.; Belfer-Cohen, A. Natufian figurines from the new excavations of the el-Wad Cave, Mt Carmel, Israel. Rock Art Res. 1993, 10, 99-103.

153. Woo Sheh Ming Research on relations between Cangyuan rock paintings and Shi-Fo-Dong Neolithic culture, pre-circulated paper, Yinchuan Rock Art Conference, China 1991.

154. You, Y. Preliminary study of a Palaeolithic bone engraving. Kexue Tongbao 1984, 29, 80-82.

(C) 2013 by the authors; licensee MDPI, Basel, Switzerland. This article is an open access article distributed under the terms and conditions of the Creative Commons Attribution license (http://creativecommons.org/licenses/by/3.0/). 